\title{
DIFFERENT WAYS TO HELP THOSE WITH MENTAL ILLNESS
}

\section{EDITED BY: Daniel F. Hermens}

PUBLISHED IN: Frontiers for Young Minds

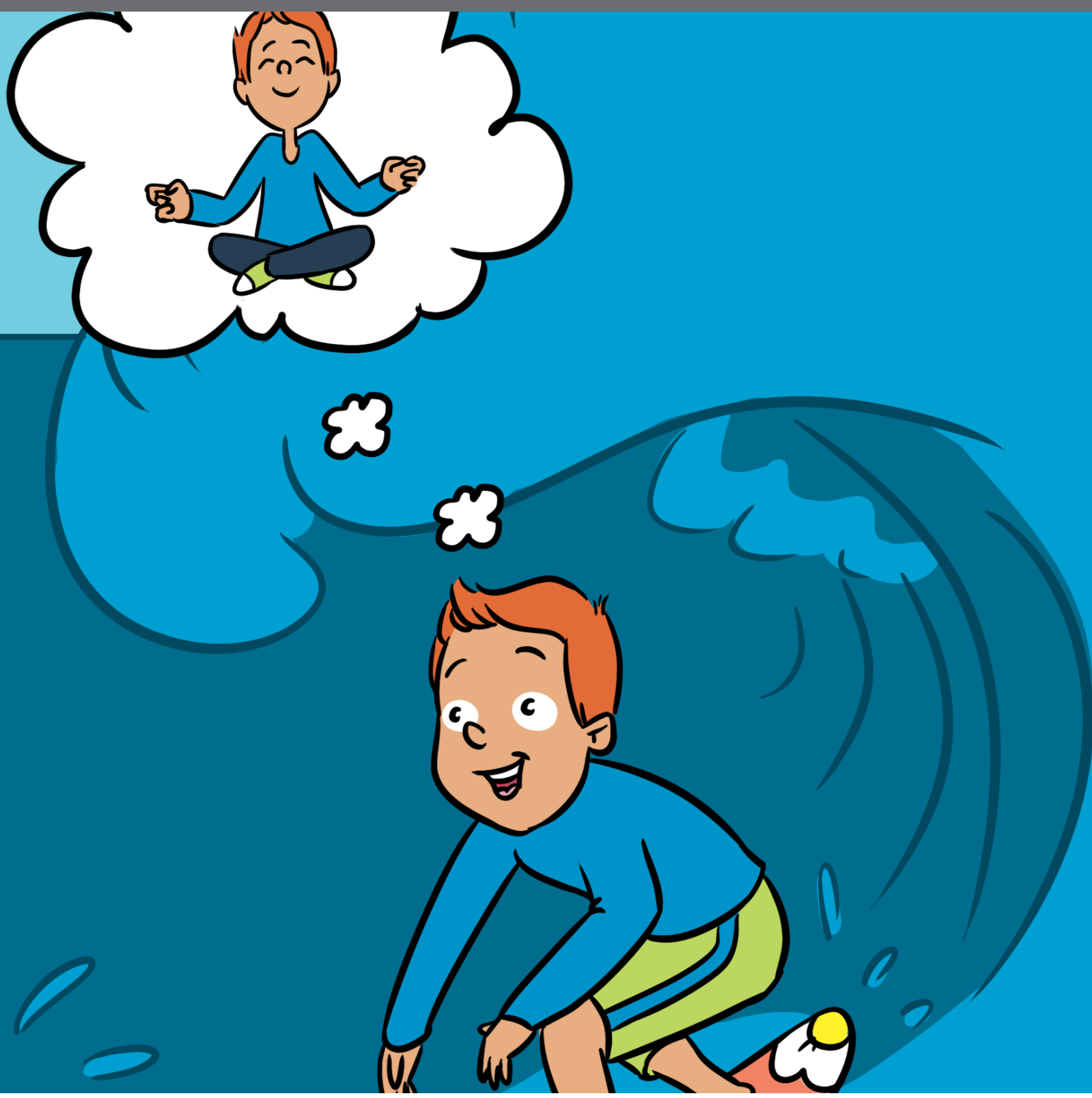




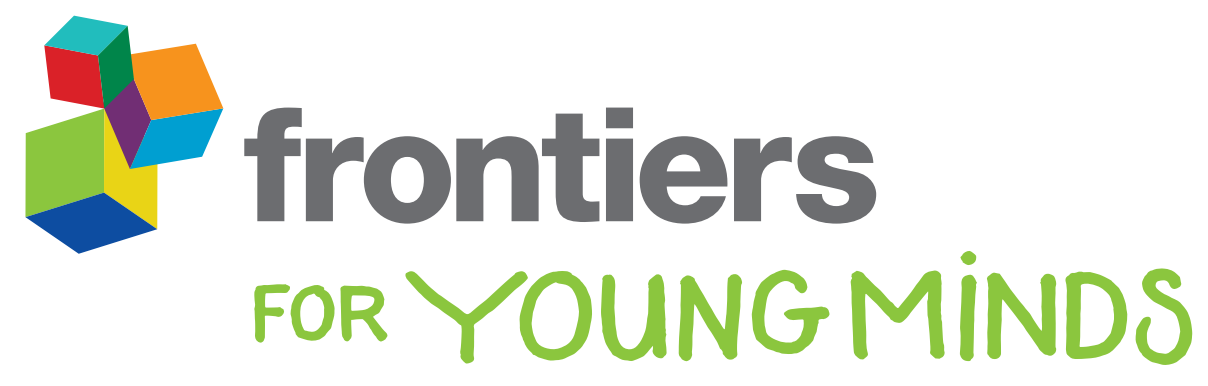

Frontiers eBook Copyright Statement

The copyright in the text of individual articles in this eBook is the property of their respective authors or their respective institutions or funders. The copyright in graphics and images within each article may be subject to copyright of other parties. In both cases this is subject to a license granted to Frontiers.

The compilation of articles constituting this eBook is the property of Frontiers.

Each article within this eBook, and the eBook itself, are published under the most recent version of the Creative Commons CC-BY licence.

The version current at the date of publication of this eBook is CC-BY 4.0. If the CC-BY licence is updated, the licence granted by Frontiers is automatically updated to the new version.

When exercising any right under the CC-BY licence, Frontiers must be attributed as the original publisher of the article or eBook, as applicable.

Authors have the responsibility of ensuring that any graphics or other materials which are the property of others may be included in the

CC-BY licence, but this should be checked before relying on the

CC-BY licence to reproduce those materials. Any copyright notices relating to those materials must be complied with.

Copyright and source acknowledgement notices may not be removed and must be displayed in any copy, derivative work or partial copy which includes the elements in question.

All copyright, and all rights therein, are protected by national and international copyright laws. The above represents a summary only.

For further information please read Frontiers' Conditions for Website

Use and Copyright Statement, and the applicable CC-BY licence.

ISSN 2296-6846

ISBN 978-2-88963-431-6

DOI 10.3389/978-2-88963-431-6

\section{About Frontiers}

Frontiers is more than just an open-access publisher of scholarly articles: it is a pioneering approach to the world of academia, radically improving the way scholarly research is managed. The grand vision of Frontiers is a world where all people have an equal opportunity to seek, share and generate knowledge. Frontiers provides immediate and permanent online open access to all its publications, but this alone is not enough to realize our grand goals.

\section{About Frontiers for Young Minds}

Frontiers for Young Minds believes that the best way to make cutting-edge science discoveries available to younger audiences is to enable young people and scientists to work together to create articles that are both accurate and exciting.

That is why distinguished scientists are invited to write about their cutting-edge discoveries in a language that is accessible for young readers, and it is then up to the kids themselves - with the help of a science mentor - to provide feedback and explain to the authors how to best improve the articles before publication.

As a result, Frontiers for Young Minds provides a collection of freely available scientific articles by distinguished scientists that are shaped for younger audiences by the input of their own young peers.

\section{What are Frontiers for Young Minds Collections?}

A Collection is a series of articles published on a single theme of research and curated by experts in the field. By offering a more comprehensive coverage of perspectives and results around an important subject of research, we hope to provide materials that lead to a higher level of understanding of fundamental science.

Frontiers for Young Minds Collections will offer our international community of Young Minds access to the latest and most fundamental research; and, most importantly, empowering kids to have their say in how it reaches their peers and the wider public. Every article is peer reviewed according to the Frontiers for Young Minds principles.

Find out more on how to host your own Frontiers for Young Minds Collection or contribute to one as an author by contacting the Frontiers Editorial Office: kidsafrontiersin.org 


\section{DIFFERENT WAYS TO HELP THOSE WITH MENTAL ILLNESS}

Topic Editor:

Daniel F. Hermens, University of the Sunshine Coast, Australia

Mental health researchers are constantly working on ways to help people with illnesses such as anxiety and depression. Unfortunately, many people of all ages are affected by mental illnesses and not all respond to traditional treatments (such as medication) or they and their doctors prefer the option to try different types of treatment. For a number of decades medications such as anti-depressants have been used by people to help treat their mental illness, and they have their pros and cons. In some cases, people may need other, more novel treatments in addition to their traditional treatments, to improve the mental health even more. So, it is important that people have some different options. But what might other treatments be? What are some of the different ways that we can help to change the brain and body to improve mental health? You might be surprised at how many good and interesting treatment choices are now available for people with mental illness.

When it comes to mental health or the treatment of mental ill-health, the brain is a very important aspect. Researchers have been able to show that mental illnesses often involve changes in the brain and so the brain is usually a 'target' of treatment. In other words, effective treatments that change how the brain functions (quickly or slowly, in big ways or small ways) often match with changes in symptoms (for example, improvement in mood or feeling less anxious). All treatments in mental health seek to improve symptoms and they often do this by helping the brain and body work better.

In this collection of articles, researchers will explain and demonstrate how things like physical exercise, meditation or magnetic stimulation work when it comes to improving symptoms of mental ill-health. Also, since the target of such interventions is typically the brain, this collection will include articles about the best ways to measure changes in the brain - such as Magnetic Resonance Imaging (MRI) that provide us with detailed pictures of brain structures, and how they are connected or disconnected.

For example, in these articles, we'll find out how surf therapy benefits people with stress-related disorders, not only because it involves physical exercise, but also because it involves risk taking and a connection with nature - how interesting is that! Importantly, researchers working with a new form of treatment are trying to demonstrate how the intervention changes brain structure and function and how these changes are linked to improved mental health. Why? So, we can better understand why some individuals respond to this treatment, whether the treatment has ongoing effects and who may benefit the most from it.

Citation: Hermens, D. F., ed. (2020). Different Ways to Help Those With Mental Illness. Lausanne: Frontiers Media SA. doi: 10.3389/978-2-88963-431-6 


\section{Table of Contents}

04 Using Magnets to Stimulate the Brain Helps People With Depression Manreena Kaur, Karyn E. Richardson and Paul B. Fitzgerald

12 A Gym Workout for Your Brain: How Mindfulness Can Help Improve Mental Health

Ben Isbel

19 The Physics of MRI and How we Use it to Reveal the Mysteries of the Mind Kathryn Mary Broadhouse

26 Muscling Up on Mental Illness: How Exercise Can Help Both Body and Mind

Grace McKeon and Simon Rosenbaum

33 How Surfing Could be a Treatment for Mental Illness

Bryan D. Peck and Jim Lagopoulos

40 What is Obsessive Compulsive Disorder?

Pedro Morgado

46 Might Lifestyle Choices Reduce the Risk of Depression?

Cristy Phillips, Aaron Baldridge, Colin Phillips, Mehmet Akif Baktir and Atoossa Fahimi 


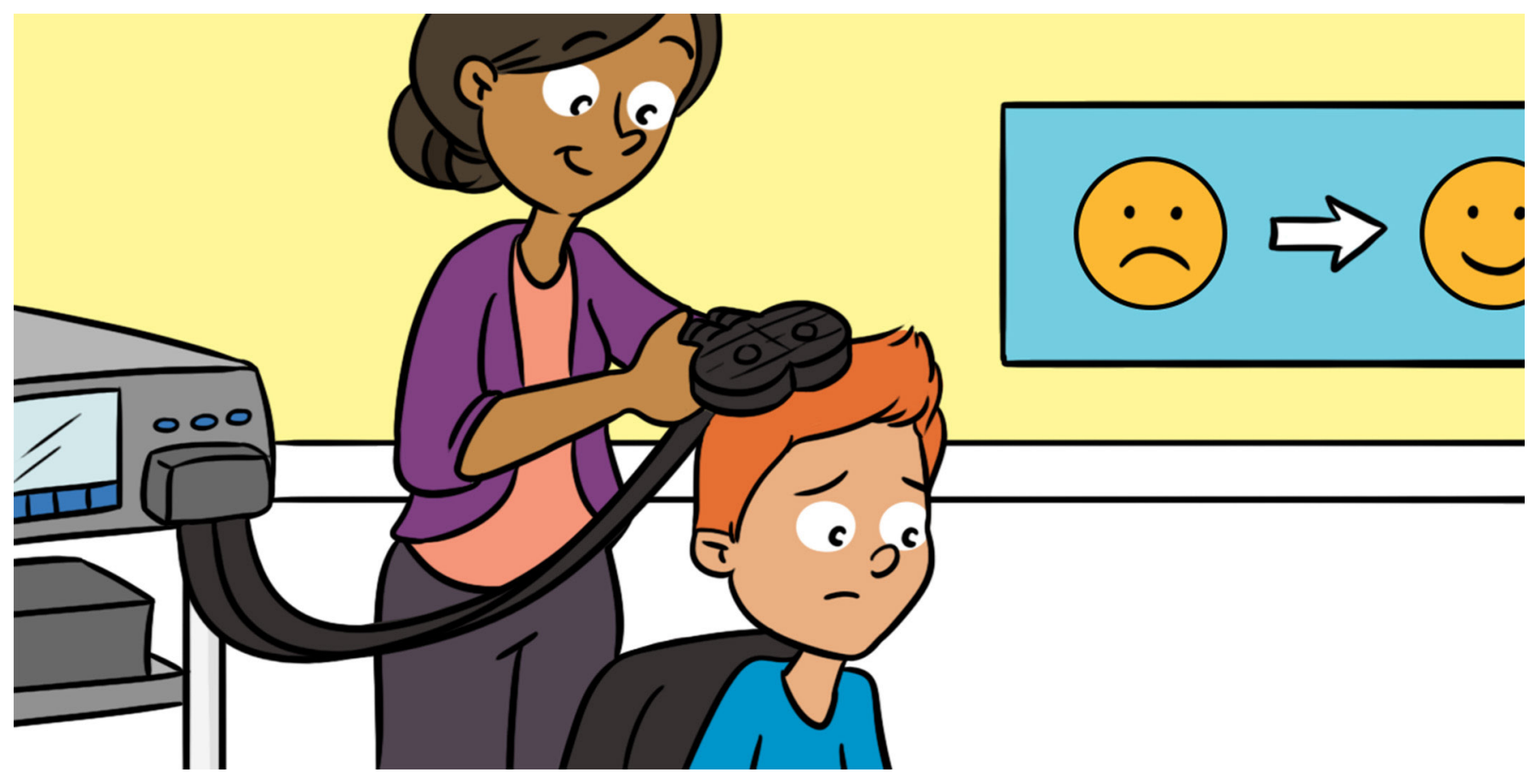

\section{USING MAGNETS TO STIMULATE THE BRAIN HELPS PEOPLE WITH DEPRESSION}

\section{Manreena Kaur ${ }^{1,2 *}$, Karyn E. Richardson ${ }^{1,2}$ and Paul B. Fitzgerald ${ }^{1,2}$}

${ }^{1}$ Monash Alfred Psychiatry Research Centre, Monash University Central Clinical School and the Alfred, Melbourne, VIC, Australia ${ }^{2}$ Epworth Centre for Innovation in Mental Health, Epworth Healthcare, Melbourne, VIC, Australia

\section{YOUNG REVIEWERS:}

\begin{tabular}{l}
\hline \\
MATTHS \\
FLINDERS \\
Anglican college
\end{tabular}

MATTHEW FLINDERS ANGLICAN COLLEGE

AGES: $14-15$
Depression is a common and disabling mental illness that can be difficult to treat and lasts a long time. Typical treatment options for depression are antidepressant medications and psychological therapies, which are helpful for some people but do not work for everyone. The underlying cause of depression is not well-understood, but one key problem is that brain cells do not communicate with each other as well as they should. Transcranial magnetic stimulation is a technique that can help to improve the communication between brain cells and this technique improves depression in many people who do not get better with antidepressant medication. However, this treatment is often not available to many patients with depression who may benefit from it, because it is expensive and takes up a lot of the patients' time. Researchers are now working toward making this treatment more accessible, so that many more people with depression can benefit from it. 


\section{NEUROTRANSMITTER}

A group of chemical messengers that are exchanged between neurons as they communicate.

\section{ACTION POTENTIAL}

The electric impulse that travels through a neuron, changing the electric charge of the neuron.

\section{SYNAPSE}

The gap in between two neurons where neurotransmitters are exchanged in communication between the two neurons.

\section{Figure 1}

(A) When a TMS pulse is applied to the brain, action potentials are generated in the neurons under the skull. (B) When an action potential happens, the electrically charged neuron becomes more positively charged, a process called depolarization. (C) When the action potential travels through the neuron, the neuron releases neurotransmitters into the synapse, the space in between neurons. The neurotransmitters are then taken up by the second neuron, triggering an action potential in that neuron.

\section{BRAIN CELLS NEED TO COMMUNICATE WITH EACH OTHER}

The human brain is made up of billions of cells called neurons. There are an average of 100 billion neurons in our brains [1]! Are you wondering how all those neurons fit inside our heads? It is because they are very small ( $<0.5 \mathrm{~mm}$ in diameter) and packed together very tightly. There are many different types of neurons and they all have different jobs. To do their jobs well, they have to work as a team and communicate with each other. It is like doing a group assignment in school, in which all the students on a team are assigned different tasks to complete the project. If one person does not do her/his part, then it will impact the rest of the team! Neurons communicate with each other through "chemical signaling," a process in which they exchange chemicals called "neurotransmitters." This is how it happens: an "action potential" is an electrical impulse that travels through a neuron, triggering it to release neurotransmitters into a small gap found in between two neurons, called a "synapse." Then, the neuron on the other side of the synapse takes up the neurotransmitters, which then generates an action potential that travels through this neuron. This process continues in several neurons that are connected to each other. Have a look at Figure $1 \mathrm{C}$ to see how neurons communicate with each other. Our abilities to pay attention to things in the environment, to remember what we learn and experience, to make decisions every day, and to manage our emotions all depend on how well our neurons work together as a team. When neurons cannot do their jobs properly, there is a domino effect on other neurons and because of this, important brain functions cannot be carried out properly. This is what happens to the brain when people experience a mental illness.

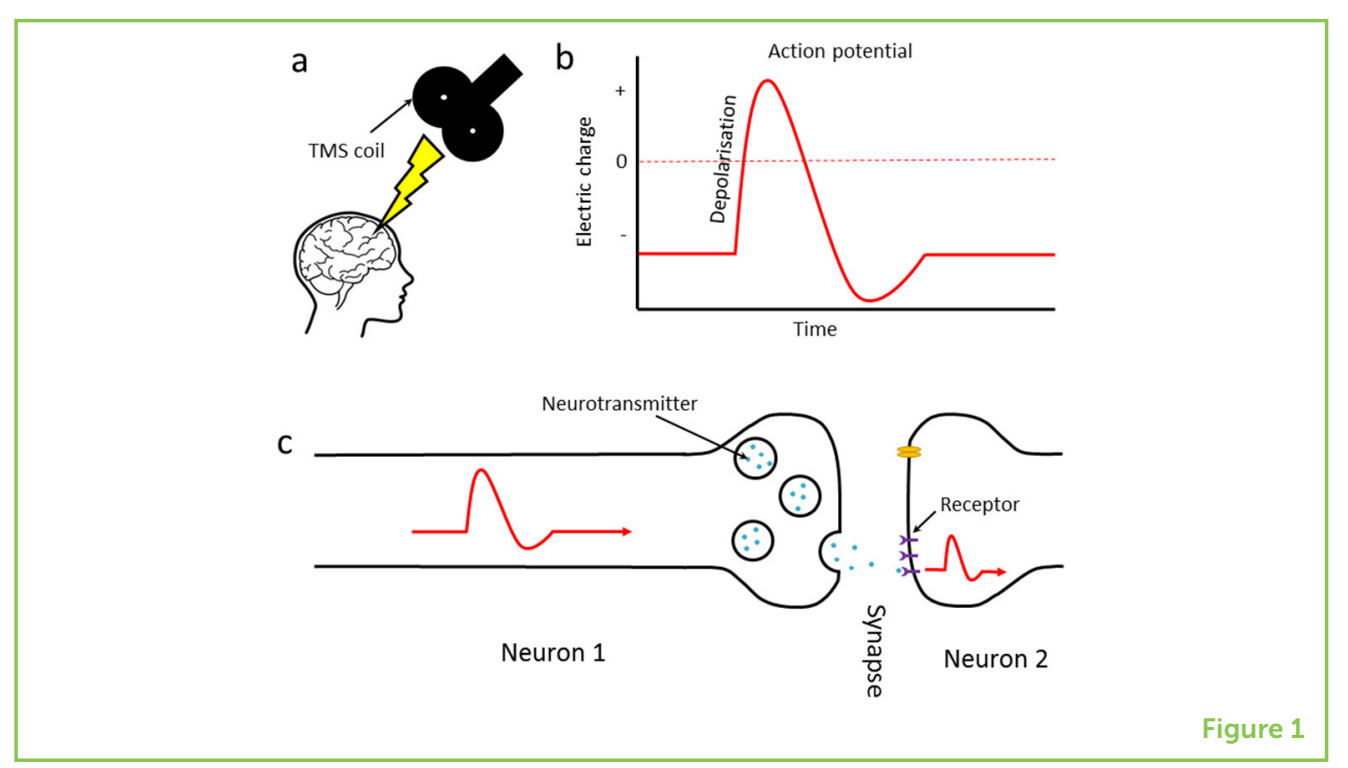




\section{WHAT IS IT LIKE TO HAVE DEPRESSION?}

Depression is the most common mental illness [2]. $4.4 \%$ of the world's population suffers from depression. This is an alarming 322 million people, which is about the total population of the U.S.A! For most people, depression starts when they are young, before 30 years of age, and as depression often lasts a long time, many people suffer from it for a large part of their lives [3]. People with depression experience prolonged periods of feeling very sad and/or lose the ability to feel pleasure. They commonly describe a feeling of emptiness, worthlessness, guilt, loss of hope, or lack of interest in many activities they used to enjoy. These feelings are often accompanied by other symptoms, such as trouble thinking clearly or carrying out day-to-day tasks, difficulty sleeping at night, feeling fatigued during the day, and reduced appetite. Depression is the leading cause of disability world-wide and many people who suffer from it cannot function well-enough to work, study, or maintain their relationships with family and friends.

\section{HOW CAN WE IMPROVE COMMUNICATION BETWEEN NEURONS TO HELP PEOPLE WITH DEPRESSION?}

Scientists do not fully understand all the complicated brain changes that cause depression. We know that there are several factors that play a role. Two of these factors are the abnormal activity of many different types of neurotransmitters and reduced ability of neurons to fix themselves when they malfunction [4]. Together, these factors result in poor communication between neurons in many regions of the brain.

Antidepressant medication can help people with depression by improving communication between neurons. While antidepressants work for many people with depression, at least half of patients are not able to achieve or sustain full recovery from their depression with antidepressants [3]. Another problem with antidepressants is that they cause undesirable side effects, such as weight gain, which can lead to other health problems. These side effects occur because medications that are swallowed are absorbed through the gut, and therefore affect cells throughout the body, not just in the brain. Psychological therapy (also called talk therapy) is also widely used to treat depression. It involves the patients seeing psychiatrists or psychologists who guide them to learn how to think about their feelings of depression differently. By training yourself to change the way you think about your feelings, you are organizing the neurons in certain regions of the brain so that they get better at communicating with each other [4]. The problem with psychological therapy is that it also does not work for all patients and 
it can take many months or even years before depression symptoms are treated. So, the treatments we typically use for depression have limitations and it is very important for researchers to find new, more effective treatments.

\section{USING A MAGNETIC FIELD TO CHANGE THE ACTIVITY OF NEURONS}

As described in 1831 by the famous physicist Michael Faraday, a brief magnetic field applied to a material that conducts electricity will generate an electrical current flow [5]. Do you remember that an action potential is an electrical impulse that travels through a neuron? This means neurons are electrically charged and can conduct electricity! So, applying a magnetic field will cause current to flow through the neurons and this can alter their activity. To alter the activity of neurons, the electric field must be strong enough to generate an electrical current in the neurons as well as in the synapses in between them [1]. When the electric charge is strong enough, the neuron will become "depolarized," meaning that it becomes more positively electrically charged. Have a look at Figure 1B showing the change in electric charge over time during an action potential. When a neuron is depolarized, an action potential is produced. When the action potential reaches the end of the neuron, it triggers the release of neurotransmitters. The neurotransmitters then attach to "receptors" on the next neuron across the synapse, and these receptors take up the neurotransmitters into the receiving neuron. This

\section{DEPOLARIZATION}

When a neuron's electrical charge becomes more positive, which occurs during an action potential.

\section{TMS}

Transcranial magnetic stimulation; a technique in which a magnetic pulse is applied to the scalp and travels through the skull to the brain, where it induces an electric current in neurons. then triggers depolarization in this neuron and then, an action potential. Figure 1 illustrates these processes. Now, can you imagine how applying current flow to neurons on the surface of the brain can set off a domino effect of communication to all the other neurons that are connected to it through synapses?

\section{STIMULATING THE BRAIN WITH MAGNETS CAN IMPROVE DEPRESSION}

In 1985, a device was invented that could alter the activity of neurons by applying a magnetic field on the scalp, a technique called TMS, which stands for transcranial magnetic stimulation [5]. Transcranial means that the magnetic field goes through the cranium (or skull) and magnetic stimulation refers to the use of a magnetic field to stimulate the neurons beneath the cranium. When TMS was first invented, researchers were very excited to use it to figure out which parts of the brain were connected to the different parts of the body. For example, they learnt that applying TMS to a certain part of the scalp made a person's hand twitch! This is how the part of the brain responsible for controlling hand 
Figure 2

Diagram of the electrical activity generated in the brain when TMS is applied to the left pre-frontal cortex. Each picture shows the brain from different angles. Cooler colors indicate increasing negative electric charge and warmer colors indicate increasing positive electric charge. These pictures clearly show how much of the brain is stimulated by TMS applied to the scalp.

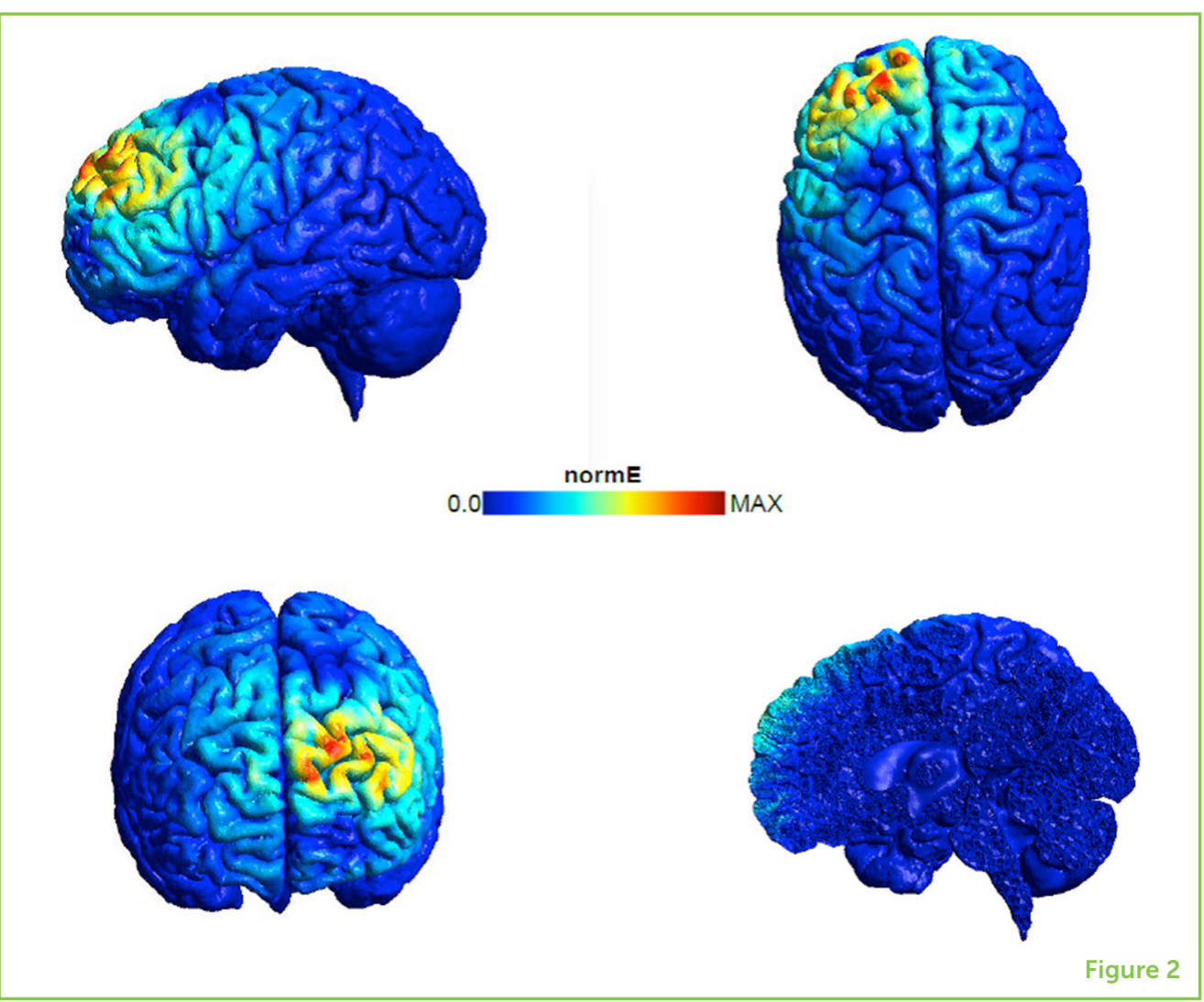

muscle movements was discovered! Interest in whether TMS could treat depression grew in the 1990's, when the first research studies using brain scanning to look at pictures of the brain in depression were carried out. These studies showed that the left side of the pre-frontal cortex, a region of the brain, was underactive in depression, leading researchers to question whether they could use TMS to increase the activity of neurons in this brain region. The initial findings of TMS applied to the left pre-frontal cortex for depression found that depression symptoms improved, which was very exciting! Have a look at Figure 2 to see the pattern of electrical activity when TMS is applied on the pre-frontal cortex of the brain.

There has been a tremendous amount of research on TMS treatment for depression in the past 20 years. Typically, TMS treatment consists of 20 min of treatment, 5 days a week, for 4 weeks. In Figure 3, you can see a photo of a patient receiving TMS. TMS is quite safe. The common side effects are mild, such as a mild headache, and severe side effects are very rare. As you can see in Figure 4, compared with antidepressant medication, there are many fewer side effects seen with TMS, and these side effects occur only around the scalp and not throughout the body. Several very careful studies performed on large numbers of patients have shown that TMS applied to the left pre-frontal cortex is effective for treating depression in people who do not improve with antidepressants. TMS has even been shown to improve the thinking skills that 


\section{Figure 3}

A patient receiving transcranial magnetic stimulation.

\section{Figure 4}

Comparison of side effects people experience with antidepressant medication versus TMS treatment. You can see that TMS treatment results in fewer side effects than antidepressant medication.

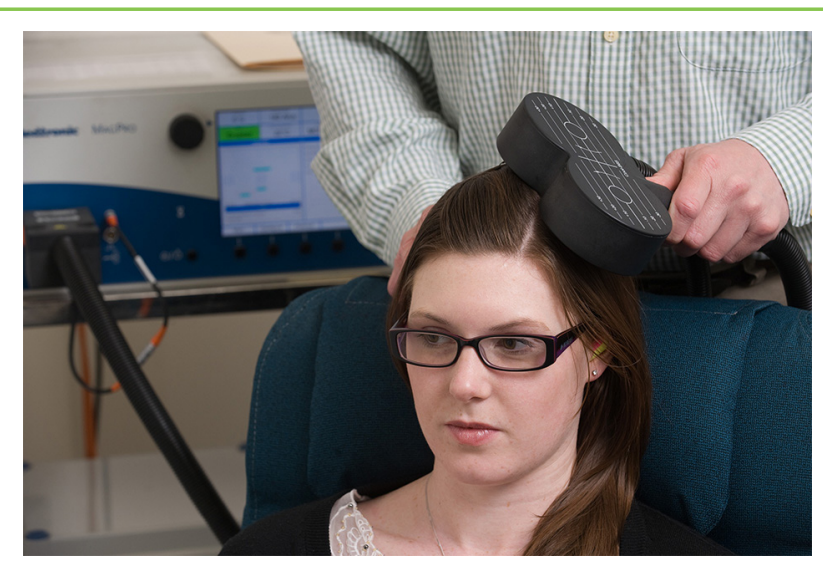

Figure 3

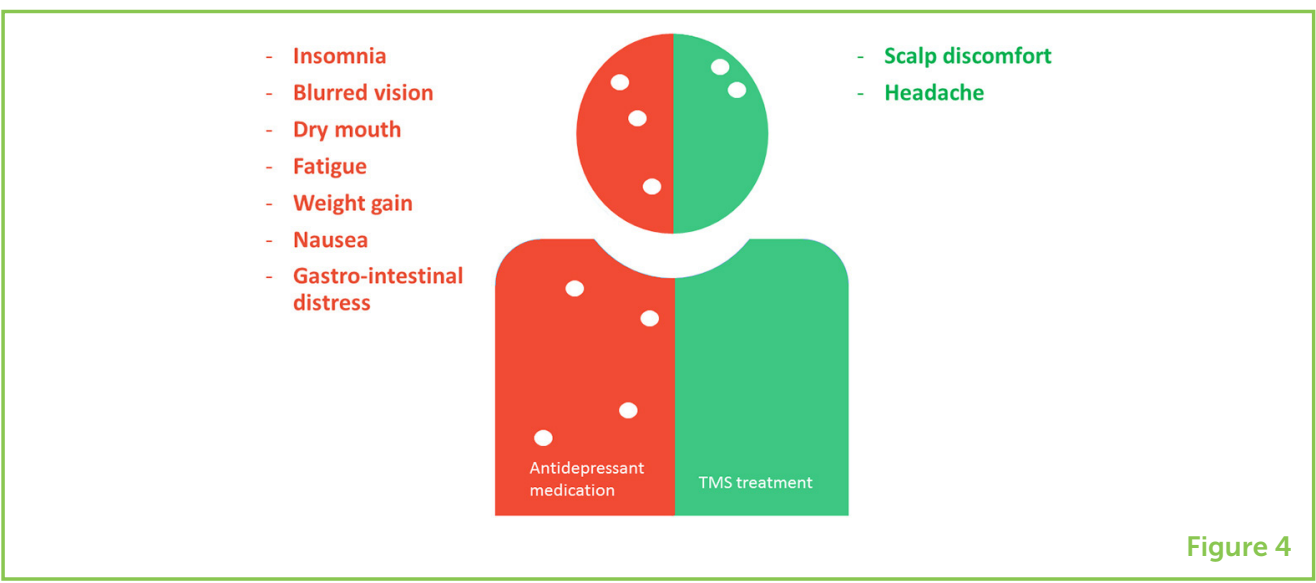

are normally affected in depression. These positive results have led to the approval of TMS as a treatment for depression by several governing bodies world-wide. However, like other depression treatments, TMS does not work for everyone-it works for about half the patients for whom medication does not work. Every year, TMS gives patients with depression new hope and changes thousands of lives. Here is an example of what one of our patients who received TMS for depression at the Monash Alfred Psychiatry Research Centre (Australia) said: "I had been in and out of hospital for months and tried every antidepressant ever made ... then my psychiatrist suggested TMS, and after the first session I already felt much better. For the first time in years, I could think clearly and make rational decisions. I felt on top of the world, like it saved my life."

\section{THE FUTURE OF TMS TREATMENT FOR DEPRESSION}

Since TMS has to be performed by medical professionals and it takes a lot of time, TMS is expensive and not all patients can afford it. Our goal now is to make TMS more accessible, so that many more patients can 
benefit from it. We are helping to make TMS accessible by researching ways to shorten the TMS treatment course and lobbying for some of the costs to be covered by health insurance or government-provided healthcare. Offering hope to patients with depression, particularly those who do not have other treatment options, makes the area of TMS research incredibly important and valuable.

\section{ACKNOWLEDGMENTS}

We would like to thank Aron T. Hill for creating Figure 3, the electrical field potential of transcranial magnetic stimulation on the left prefrontal cortex.

\section{REFERENCES}

1. Wickens, A. 2009. Introduction to Biopsychology. Harlow: Pearson Education.

2. World Health Organization. 2017. Depression and Other Common Mental Disorders: Global Health Estimates. Geneva: World Health Organization.

3. McIntyre, R. S., Filteau, M. J., Martin, L., Patry, S., Carvalho, A., Cha, D. S., et al. 2014. Treatment-resistant depression: definitions, review of the evidence, and algorithmic approach. J. Affect. Disord. 156:1-7. doi: 10.1016/j.jad.2013.10.043

4. Dean, J., and Keshavan, M. 2017. The neurobiology of depression: an integrated view. Asian J. Psychiatr. 27:101-11. doi: 10.1016/j.ajp.2017.01.025

5. Fitzgerald, P. B., and Daskalakis, Z. J. 2013. Repetitive Transcranial Magnetic Stimulation Treatment for Depressive Disorders: A Practical Guide. Berlin; Heidelberg: Springer Science \& Business Media.

SUBMITTED: 19 September 2018; ACCEPTED: 05 February 2019; PUBLISHED ONLINE: 20 February 2019.

EDITED BY: Daniel F. Hermens, Sunshine Coast Mind and Neuroscience Thompson Institute, University of the Sunshine Coast, Australia

CITATION: Kaur M, Richardson KE and Fitzgerald PB (2019) Using Magnets to Stimulate the Brain Helps People With Depression. Front. Young Minds 7:26. doi: 10.3389/frym.2019.00026

CONFLICT OF INTEREST STATEMENT: In the last 3 years, PF has received equipment for research from Magventure A/S, Medtronic Ltd, Neurosoft and Brainsway Ltd. He has served on a scientific advisory board for Bionomics Ltd and LivaNova and is a founder and board member of TMS Australia. The remaining authors declare that the research was conducted in the absence of any commercial or financial relationships that could be construed as a potential conflict of interest. 

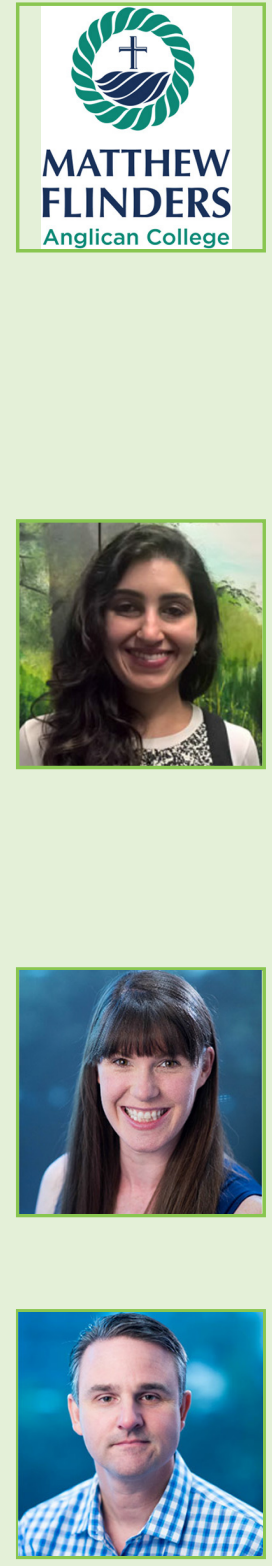

COPYRIGHT () 2019 Kaur, Richardson and Fitzgerald. This is an open-access article distributed under the terms of the Creative Commons Attribution License (CC BY). The use, distribution or reproduction in other forums is permitted, provided the original author(s) and the copyright owner(s) are credited and that the original publication in this journal is cited, in accordance with accepted academic practice. No use, distribution or reproduction is permitted which does not comply with these terms.

\section{YOUNG REVIEWERS}

\section{MATTHEW FLINDERS ANGLICAN COLLEGE, AGES: 14-15}

Matthew Flinders Anglican College young reviewers are keen budding scientists who enjoy taking on challenges. They are a collaborative bunch of young minds, with shared interests in science, music, and sport. This group of young reviewers thoroughly enjoy being part of Frontiers for Young Minds and are excited to be involved in how science is being communicated and shaped.

\section{AUTHORS}

\section{MANREENA KAUR}

As a Research Fellow at the Monash Alfred Psychiatry Research Centre, the focus of my research is on investigating treatments using brain stimulation techniques for depression and schizophrenia, particularly for young people. I have always been fascinated by how the body, brain, and mind work and I am dedicated to improving the lives of people with mental illness by helping to provide new treatment options for them. When I am not doing Science, I love to listen and explore new music, travel around the world, and hang out with my friends and family! *manreena.kaur@monash.edu

\section{KARYN E. RICHARDSON}

I am a Researcher and Psychologist with a passion for understanding how the brain works and influences the way we behave. I have worked on a number of studies using brain stimulation to treat depression and am interested in learning how we could use brain stimulation to help people who have experienced a stroke. In my free time, I enjoy spending time with family in the outdoors.

\section{PAUL B. FITZGERALD}

I am a Professor of Psychiatry at the Epworth Clinic and Monash Alfred Psychiatry Research Centre. Through my work as a Psychiatrist, I saw a strong need for more effective treatments for people with mental illness. I have since dedicated my career to understanding how the brain works and developing new brain stimulation treatments for people with mental illness. I also work to make these treatments easily accessible for patients. My interest in magnetic and electrical brain stimulation treatments may or may not have anything to do with have been struck by lightning when I was in my early 20 s. 

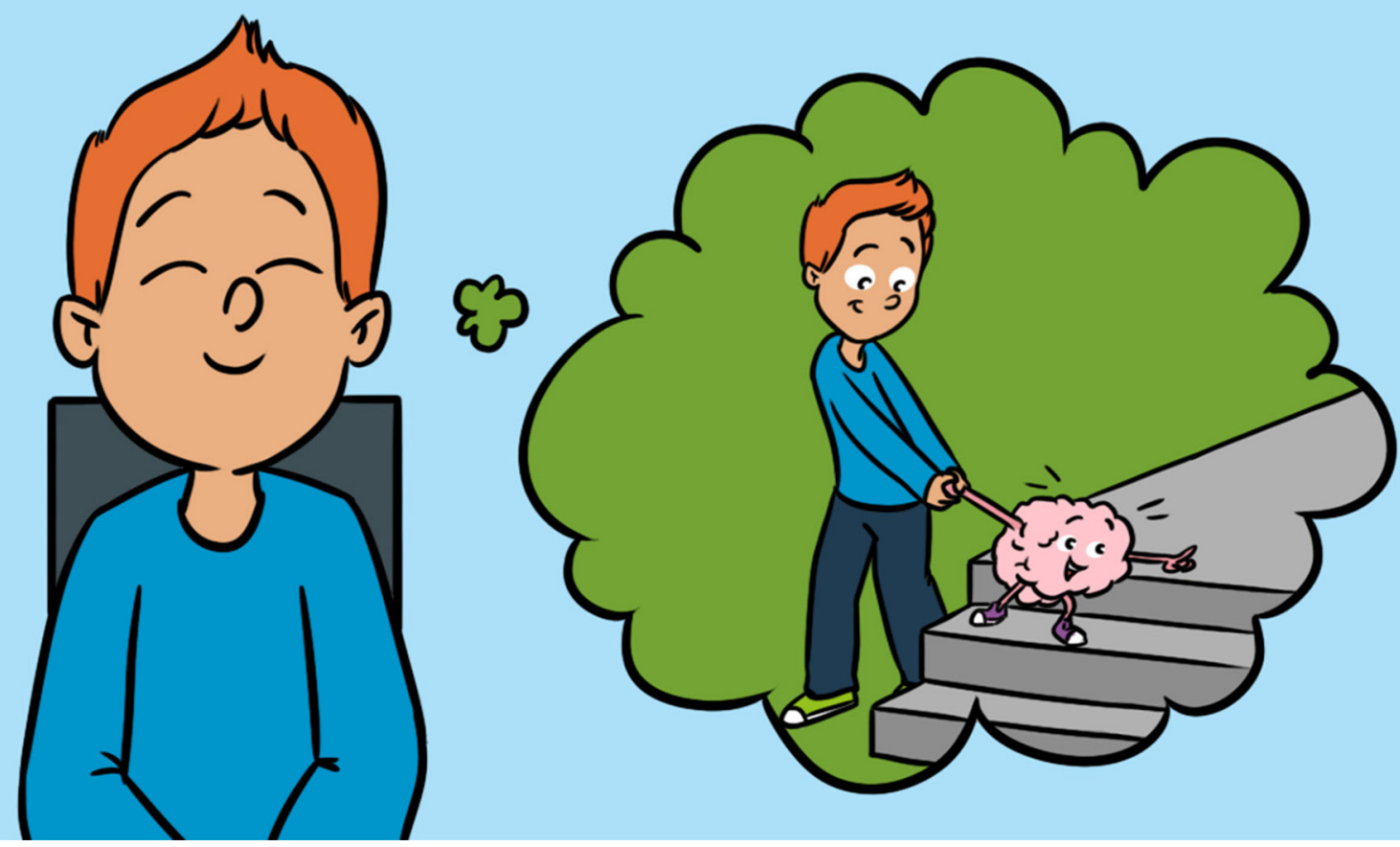

\section{A GYM WORKOUT FOR YOUR BRAIN: HOW MINDFULNESS CAN HELP IMPROVE MENTAL HEALTH}

\section{Ben Isbel*}

Sunshine Coast Mind and Neuroscience-Thompson Institute, University of the Sunshine Coast, Sippy Downs, QLD, Australia

\section{YOUNG REVIEWERS:}

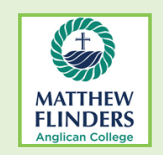

MATTHEW

FLINDERS

ANGLICAN

COLLEGE

AGES: $14-15$
You probably know that going to the gym to exercise is good for your body. Exercise keeps us fit and healthy. Did you know that you can also exercise your mind to keep it fit and healthy? Mindfulness training is just like taking your brain to the gym for a workout. When we practice mindfulness, we are training our attention to stay in the present moment instead of wandering off with our thoughts into the past or the future. By keeping our attention in the present, and bringing it back each time it wanders, we are training the brain networks that we use to control our attention. This type of training can improve our mental health, just like physical exercise improves our physical health.

\section{DOES MINDFULNESS MEAN MY MIND IS FULL?}

Have you ever been so deep in thought that you did not hear someone calling your name? At times like these, our minds are full of thoughts 


\section{MINDFULNESS}

The ability to pay attention to the present moment, without judgment or reaction

\section{ATTENTION}

The brain's ability to focus on one thing out of a wide range of objects.

\section{Figure 1}

When we bring full awareness to what is happening in the mind we have mindfulness. and we are not aware of what is going on around us. Often, we are busy thinking about what is going to happen later, thinking about what happened earlier, or thinking about what is happening now. It can certainly seem like our minds are full of thoughts! But that is not what mindfulness means. Mindfulness means being aware of what is happening now, without getting lost in all of those thoughts. Mindfulness helps us become more aware of what is going on both outside and inside of ourselves, without being distracted by our thoughts. With mindfulness, we can be fully aware of our minds (see Figure 1).

\section{EXERCISE FOR THE MIND}

Just as we need to exercise our bodies to stay physically healthy, exercising our minds can keep us mentally healthy, too. Mindfulness involves training our attention to stay in the present moment, rather than following our thoughts into the past or future. The same way we do certain exercises to strengthen our body's muscles, with mindfulness we train the brain's muscle-attention.

Attention is the brain's way of selecting one thing to focus on out of the wide range of things in the environment. The brain is constantly receiving information about the world around us from our five senses, as well as interpreting that information using lots of thoughts. There is so much going on in the environment, but we often need to select one thing to focus on, without getting distracted. Attention's job is to keep that one thing in mind, so we can focus on it. Attention is one of the most important brain functions. When attention does not work well we have lots of difficulties, such as attention deficit hyperactivity disorder (ADHD). In ADHD, people have trouble keeping their minds on one task, which makes it hard to concentrate when trying to solve a math problem at school, for example.

\section{Mind + full awareness}

\section{Mind + fultawareness}

\section{Mindfulness}


When you focus on something, you are using networks made up of brain cells called neurons. When you do physical exercise to strengthen a muscle, you train that muscle by repeating the exercise again and again. In mindfulness, you can target these brain networks by making your attention stay on one thing without getting distracted. And when you do get distracted, you bring your attention back again and again. It is like a gym workout for your brain! Scientists have discovered that this kind of exercise can benefit mental health [1].

\section{MINDFULNESS}

Let us try a mindfulness exercise right now.

Start by sitting down either on the floor or on a chair with your back nice and straight. As you sit, just relax. Be aware of your body as you sit still. While you are sitting still, notice the rising and falling of your belly as you breathe in and out. Do not try to make your breath deeper or longer, but just let it be. Just feel it. Can you feel the sensations of movement as your belly goes up and down with the breath? Try not to think about these movements. Just pay attention to the sensations of the rising and falling of the belly as you breathe in and out. Without following thoughts as they arise, just stay with the feeling of the rising and falling.

It would not be long before you start thinking of something other than your breath. Your attention will want to follow a thought, since watching the breath can be pretty boring! We usually like to pay attention to things that are exciting. But, by stopping your attention from following thoughts and just returning it to the rising and falling of your breath, you are training several attentional networks in your brain.

- When you focus on the breath, you use a brain network for focused attention.

- When you notice a wandering thought, you use a brain network for detecting distraction.

- When you stop that wandering thought, you use a brain network to prevent your attention from following that thought.

- When you return your attention back to the breath, you use a brain network for redirecting attention.

When we practice mindfulness, we are always getting distracted from the breath, so we have to activate all of these networks over and over again (see Figure 2). This is why mindfulness can seem like hard work. Because it is! We are really giving the brain a workout when we try to keep our attention on the breath. 
Figure 2

The process of controlling attention during mindfulness practice. First, try to follow the feeling of your breath. When your mind wanders, notice that is happening and bring the attention back to the breath. Repeat this again and again! It is like a gym workout for your brain!

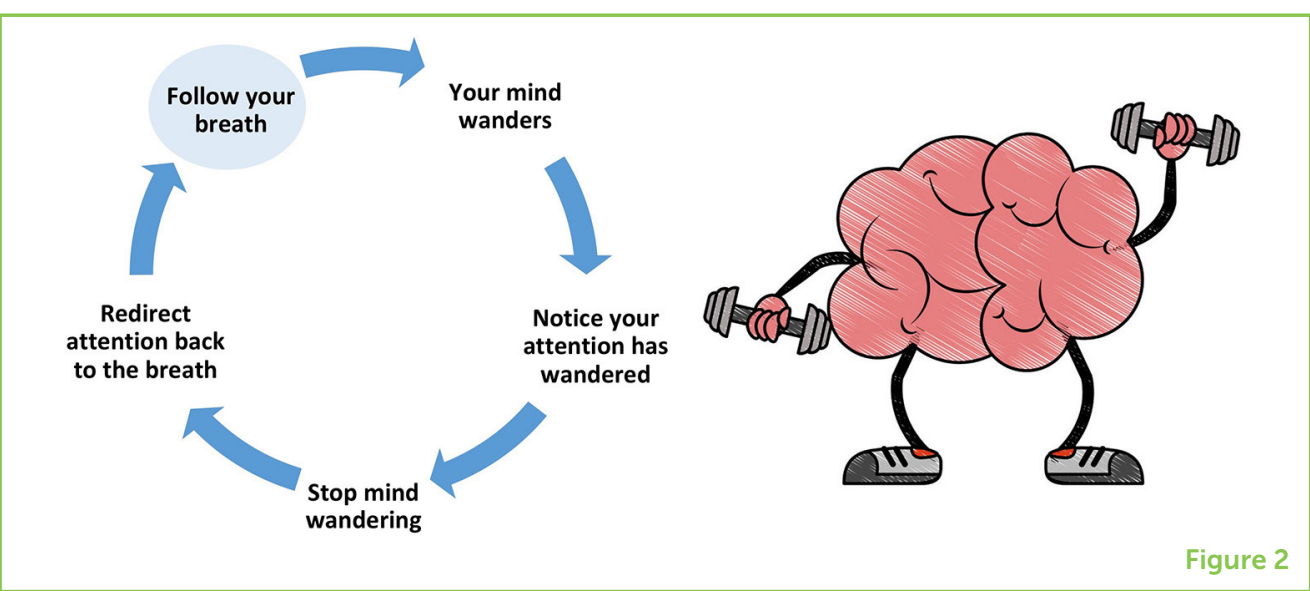

An important part of mindfulness is paying attention without reacting to what is going on. It is easy to get frustrated by your wandering mind. While you are trying to follow the rising and falling of the breath, just pay attention without reacting to what you are experiencing. Do not worry about whether it is easy or difficult. If you react to what is happening, you are just thinking even more thoughts! Just let your attention rest on the breath. And when it wanders, bring it back each time.

Can you do it for 1 min? Have a try!

\section{WHAT HAPPENS TO A WANDERING MIND?}

Scientists have discovered that the more our thoughts wander the greater chance we have of being unhappy [2]. When we keep thinking about something bad that happened in the past, we could become depressed. If we keep worrying about something bad that might happen in the future, we could become anxious. Being depressed and anxious occur when our thoughts take us away from what is happening right now, into the past or the future.

Neuroscientists (scientists who study the brain) have found that depression and anxiety are associated with changes in the brain. Scientists can measure the activity of neurons in the brain using a device called an electroencephalograph, or EEG. An EEG measures brain activity by recording the electrical signals produced by the neurons (see Figure 3).

These electrical signals are measured using electrodes placed on the scalp. If electrical activity is measured on both sides of the brain, neuroscientists can see if the activity is the same on both sides. If there is asymmetry (lack of equality) between the two sides of the brain, neuroscientists can see if there is relatively more right-sided or left-sided brain activity. 


\section{Figure 3}

This girl is having her brain activity measured by EEG. The wires in this cap are connected to small electrodes that record the electrical activity produced by neurons in the brain. In this way, scientists can measure whether there is more left or right sided brain activity. Greater left-sided brain activity is associated with positive feelings.

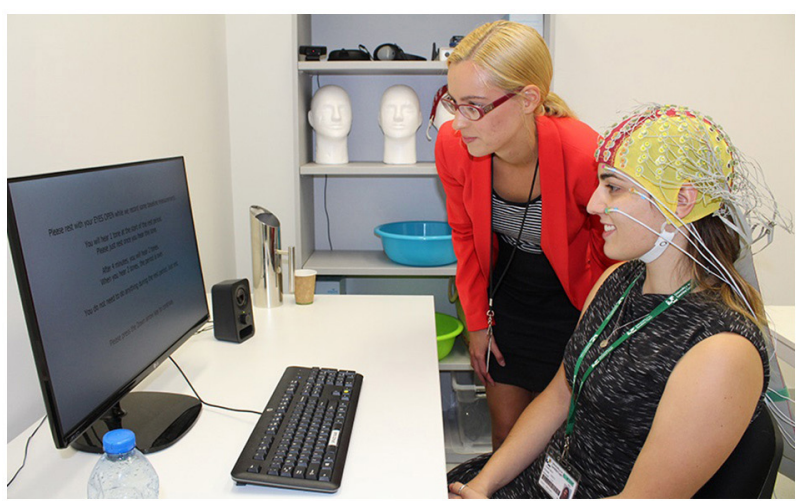

Figure 3

Studies have shown that greater left-sided brain activity is associated with positive feelings and behavior, while greater right-sided brain activity is associated with more negative feelings and behavior [3]. People with depression and anxiety have been shown to have higher levels of right-sided brain activity than people without these conditions [4].

\section{PAYING ATTENTION TO THE PRESENT IS GOOD FOR US}

By now, you might be wondering why you have to pay attention to the breath when you are practicing mindfulness. The breath has one very special feature. It only occurs now, in the present moment. If you are paying attention to your breath, you must be paying attention to what is happening right now. When your thoughts wander, you lose the present moment. But you can always come back to the present by remembering the breath.

Scientific studies are beginning to show that mindfulness practice may result in increased left-sided brain activity [5]. This increase in left-sided activity may also be accompanied by more positive feelings and well-being. This is really good news, because it means that we can change our brains just by training the way we pay attention. By training our attention to stay in the present moment, we can keep our minds from running off into the past and the future and worrying about all of those things. And this may change our brains in ways that help us feel better.

\section{REFERENCES}

1. Gotink, R. A., Chu, P., Busschbach, J. J. V., Benson, H., Fricchione, G. L., and Hunink, M. G. M. 2015. Standardised mindfulness-based interventions in 
healthcare: an overview of systematic reviews and meta-analyses of RCTs.

PLOS ONE 10:e0124344. doi: 10.1371/journal.pone.0124344

2. Killingsworth, M. A., and Gilbert, D. T. 2010. A wandering mind is an unhappy mind. Science 330:932. doi: 10.1126/science.1192439

3. Tomarken, A. J., Davidson, R. J., Wheeler, R. E., and Doss, R. C. 1992. Individual differences in anterior brain asymmetry and fundamental dimensions of emotion. J. Pers. Soc. Psychol. 62:676-87. doi: 10.1037/00223514.62.4.676

4. Adolph, D., and Margraf, J. 2017. The differential relationship between trait anxiety, depression, and resting frontal $\alpha$-asymmetry. J. Neural Transm. (Vienna) 124:379-86. doi: 10.1007/s00702-016-1664-9

5. Zhou, R., and Liu, L. 2017. Eight-week mindfulness training enhances left frontal EEG asymmetry during emotional challenge: a randomized controlled trial. Mindfulness 8:181-9. doi: 10.1007/s12671-016-0591-z

SUBMITTED: 24 September 2018; ACCEPTED: 15 February 2019; PUBLISHED ONLINE: 01 March 2019.

EDITED BY: Daniel F. Hermens, Sunshine Coast Mind and Neuroscience Thompson Institute, University of the Sunshine Coast, Australia

CITATION: Isbel B (2019) A Gym Workout for Your Brain: How Mindfulness Can Help Improve Mental Health. Front. Young Minds 7:34. doi: 10.3389/ frym.2019.00034

CONFLICT OF INTEREST STATEMENT: The author declares that the research was conducted in the absence of any commercial or financial relationships that could be construed as a potential conflict of interest.

COPYRIGHT @ 2019 Isbel. This is an open-access article distributed under the terms of the Creative Commons Attribution License (CC BY). The use, distribution or reproduction in other forums is permitted, provided the original author(s) and the copyright owner(s) are credited and that the original publication in this journal is cited, in accordance with accepted academic practice. No use, distribution or reproduction is permitted which does not comply with these terms.

\section{YOUNG REVIEWERS}

\section{MATTHEW FLINDERS ANGLICAN COLLEGE, AGES: 14-15}

Matthew Flinders Anglican College young reviewers are keen budding scientists who enjoy taking on challenges. They are a collaborative bunch of young minds, with shared interests in science, music, and sport. This group of young reviewers thoroughly enjoys being part of Frontiers for Young Minds and is excited to be involved in how science is being communicated and shaped. 


\section{AUTHOR}

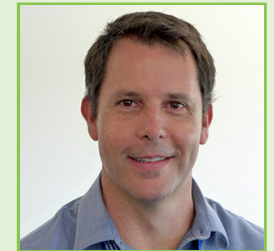

\section{BEN ISBEL}

I am a Neuroscientist interested in ways that we can improve attention and cognition using mindfulness training. I work at the Sunshine Coast Mind and NeuroscienceThompson Institute in Australia, where I specialize in EEG techniques to study the brain. *ben.isbel@research.usc.edu.au 


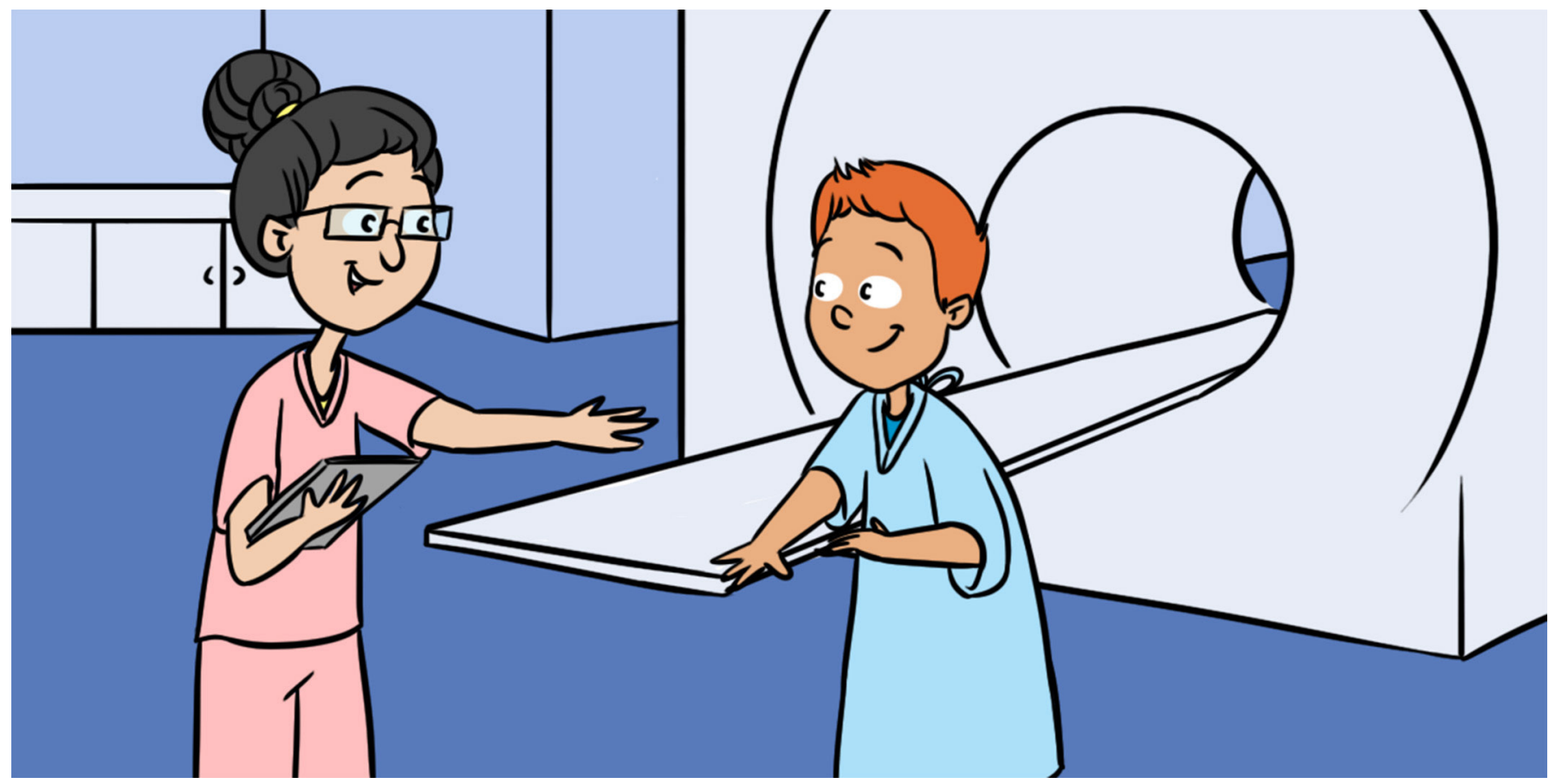

\section{THE PHYSICS OF MRI AND HOW WE USE IT TO REVEAL THE MYSTERIES OF THE MIND}

\section{Kathryn Mary Broadhouse*}

Sunshine Coast Mind and Neuroscience Thompson Institute, University of the Sunshine Coast, Sunshine Coast, QLD, Australia

\section{YOUNG REVIEWERS:}

\begin{tabular}{|l|}
\hline \\
MATTHEW \\
FINDERS \\
Anglican College
\end{tabular}

MATTHEW FLINDERS ANGLICAN COLLEGE AGES: $14-15$
Our ability to interpret and process information and regulate emotion is determined by the structure and chemical makeup of our brains. A change to the structure or biochemical makeup of our brains can affect our mental health, the way we cope with the normal stresses of life, our productivity, and our overall well-being. Scientists interested in studying the brain and mental health disorders (called neuroscientists) seek to understand how the architecture and biochemical makeup of the brain differs in health and disease. To do this, we use a technique called magnetic resonance imaging (MRI) to image inside the living brain, to examine its function and structure. This article explains the physics of MRI and how we use it to generate images of our brains in order to investigate how the mind works.

\section{THE BRAIN: HOME OF THE MIND}

As the center of the nervous system, the brain makes sense of the information from our surroundings. The brain interprets information 
and both releases chemicals and sends electrical signals (messages) to cause the body to respond. However, our brains not only regulate our bodies and our movements but are also the home of our minds. The brain is the physical place where the mind resides.

Our minds constantly control the flow of information-our memories, thoughts, emotion, and imagination. This flow of information (Figure 1A) can be thought of as a social network where, instead of messages being sent between friends on social media, information is being sent to different parts of the brain along neurons. The mind's network relies on the underlying structure and chemical makeup of the brain to function successfully. In fact, a successful or effective mind network allows us to be cognitively (our ability to carry out mental activities), emotionally, and socially healthy.

\section{MENTAL HEALTH}

The mind network, the way it sends information and its underlying structure determine our mental health. In mental health disorders, such as depression and anxiety, we often see a disruption to the mind network (Figure 1B). This change to the underlying structure and chemical makeup of our brains can affect the way we can cope with the normal stresses of life, our productivity, and our overall wellbeing. Therefore, neuroscientists who want to understand mental health disorders and how we can all stay mentally healthy seek to examine the mind network. If we can understand how the brain's structure and chemical makeup lead to healthy function, then we can start to understand brain disorders. However, to be able to study the mind and its network, we need to be able to look inside people's brains. To do this we use MRI.

A) Flow of information our emotions, and our thoughts can be thought of as a social network where, instead of messages being sent between friends on social media, information is being sent to different parts of the brain along neurons. (B) In mental health disorders, such as depression and anxiety, we often see a disruption to the mind network. This disruption can affect the way the mind network sends, receives, or interprets messages.
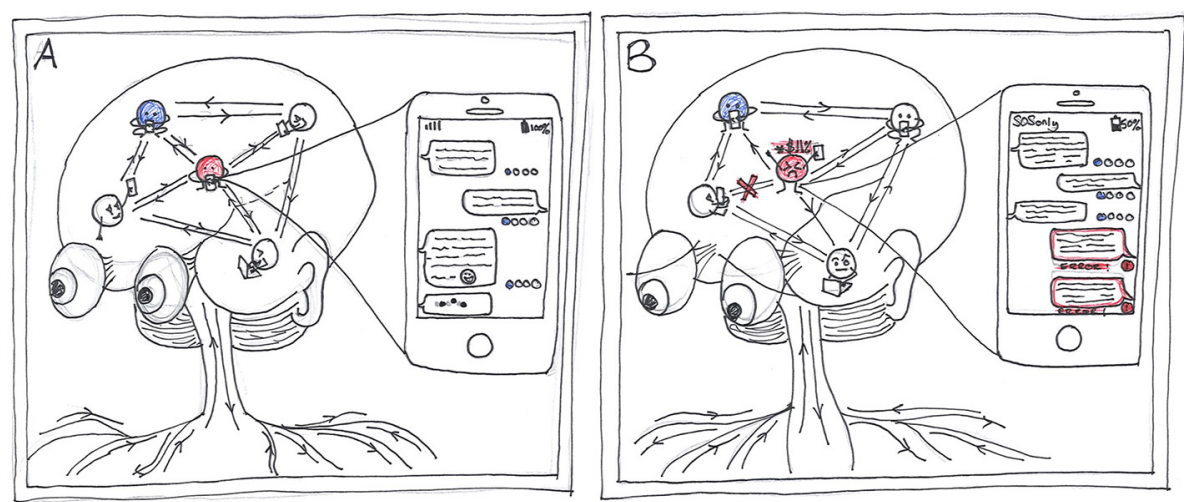

Figure 1 


\section{MAGNETIC RESONANCE IMAGING: MRI}

Magnetic resonance imaging (MRI) allows us to see inside the human body with amazing detail, by using magnets and radio waves. The first MRI scanner used to image the human body was built in New York in 1977. Since then, the technology has come a long way and MRI is now used frequently by doctors to look inside the human body. This is because MRI does not involve radiation (like an X-ray or CT scan) and there are more and more MRI scanners being installed around the world.

\section{THE "MAGNET" IN MAGNETIC RESONANCE IMAGING}

The MRI scanner is essentially a giant magnet. The strength of the magnet is measured in a unit called Tesla (T). Most MRI scanners used in hospitals and medical research clinics are 1.5 or $3 \mathrm{~T}$. Putting that in to

Figure 2

Hydrogen protons and how they behave in a magnetic field.

(A) Water is made up of two hydrogen atoms and one oxygen atom. The hydrogen nucleus (shown in red as $\mathrm{P}+$ ) contains one positive charge-a proton spinning around on its axis, which acts like a tiny magnet. (B) In the MRI scanner, the protons align with the BO magnetic field, some "up" (red), and slightly less "down" (white). The total magnet field generated from all the hydrogen protons almost cancel each other out, to leave only the magnetic field from the small proportion of extra "up" protons, and it is this small magnetic field that we can measure using MRI. (C) When an RF wave/pulse with the same frequency as the proton's precessional frequency is turned on, the "up" protons flip away from the BO field, as they absorb the RF energy. perspective, the earth's magnetic field is around $0.00006 \mathrm{~T}$. A 3 T MRI scanner is around 60,000 times stronger than the earth's magnetic field!

MRI uses magnetic fields and radio waves to measures how much water is in different tissues of the body, maps the location of the water and then uses this information to generate a detailed image. The images are so detailed because our bodies are made up of around $65 \%$ water, so we have lots of signal to measure. The water molecule $\left(\mathrm{H}_{2} \mathrm{O}\right)$ is made up of two hydrogen atoms and one oxygen atom. The hydrogen $(\mathrm{H})$ atoms are the part that makes water interesting for MRI, and what we use to measure the signal from the body when we do an MRI scan.

If we look at hydrogen in more detail, we see it has a central nucleus containing a single positive charge, called a proton (Figure 2A). Like the Earth spinning on its axis with a north and south magnetic pole,

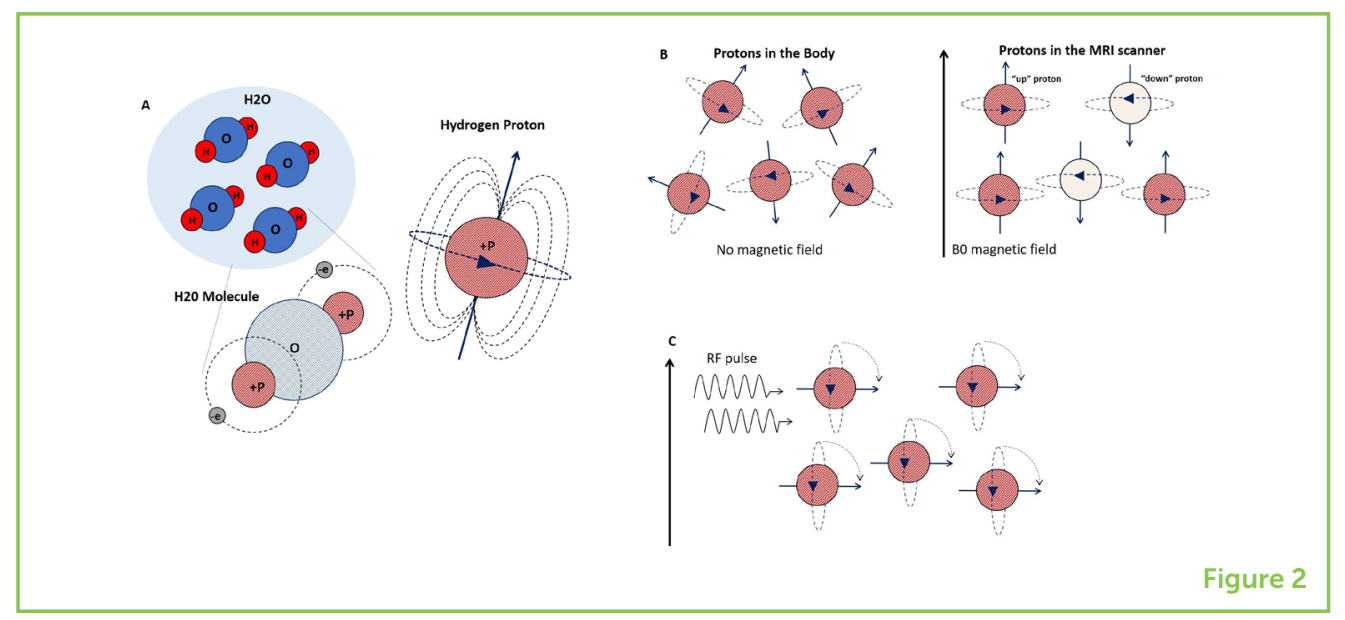


BO

The MRI scanner's main magnetic field.

PRECESSIONAL

FREQUENCY

The rate at which protons spin in a magnetic field.

RF

Radio frequency pulse used to tip on resonance protons away from the BO field.

ON RESONANCE

Have the same frequency. each spinning hydrogen proton is like a tiny magnet that spins around on its own axis. This spinning motion is known as precession. At any moment in time, all the billions of hydrogen protons in our bodies are all in random positions and spinning on their axes.

However, this randomness changes when we place a human body into a very strong magnetic field, like an MRI scanner. Just like a compass needle aligns to the Earth's magnetic field, when these randomly spinning hydrogen protons are placed in an MRI scanner, their axes realign them with the scanner's stronger magnetic field. We call the scanners magnetic field the BO field. Just like a compass needle in the earth's field, the compass itself does not physically move, but rather the needle spins to align itself. Similarly, the hydrogen protons do not physically move in your body when you enter an MRI scanner, their axes just align along the direction of the BO field. Some will align "up" (parallel) and some will align "down" (anti-parallel), while still spinning around on their own axes (Figure 2B). Due to the wonderful laws of quantum physics, which we will not go into here, there are always just slightly more "up" protons than "down." If you now think about the total magnet field generated from all our hydrogen protons, these tiny magnets almost cancel each other out, to leave only the magnetic field from the small proportion of extra "up" protons, and it is this small magnetic field that we can measure using MRI.

The BO field not only affects the hydrogen proton's alignment, but also affects how fast these protons spin (called precessional frequency). The precessional frequency depends on the strength of the magnetic field. The stronger the magnetic field, the faster they spin. These two ideas of axis realignment and precessional frequency are important when we use MRI to measure the signal from these hydrogen molecules.

\section{HOW DO WE DETECT THE MAGNETIC FIELD?}

So how do we distinguish the tiny magnetic field caused by the extra "up" hydrogen protons in our body from the massive B0 field of the scanner? We use something called a radio frequency (RF) pulse, to disturb or flip all the protons, at the same time, out of alignment from the scanners magnetic field (Figure 2C). The frequency of the RF pulse must be the same as the frequency of the spinning hydrogen protons, so they can exchange energy, so that they are on resonance with each other. Resonance enables the protons to absorb enough energy from the RF pulse to rotate their axes away from the BO field, so that the MRI scanner can measure it. If we think again about our compass in the Earth's magnetic field pointing toward the north pole, we can make 
Figure 3

Focusing our imaging.

(A) The B1 field is applied, which increases across the body, from foot to head. Hydrogen protons in the head wil then be spinning faster than those in the feet

(B) Different tissues, such as white matter, gray matter and cerebral spinal fluid (CSF) in the body give off different amounts of energy. To measure the energy emitted by the protons in the brain when the RF pulse is turned off, we place a coil around the head.

(C) This technique can provide many different images of the brain, giving us information about (top right): how the brain is structurally connected via white matter-the information highways of the brain (Middle right): the volume of gray matter regions of the brain, where information is processed. (Bottom right): how the brain is functionally connected-how different regions of the brain communicate and work together.

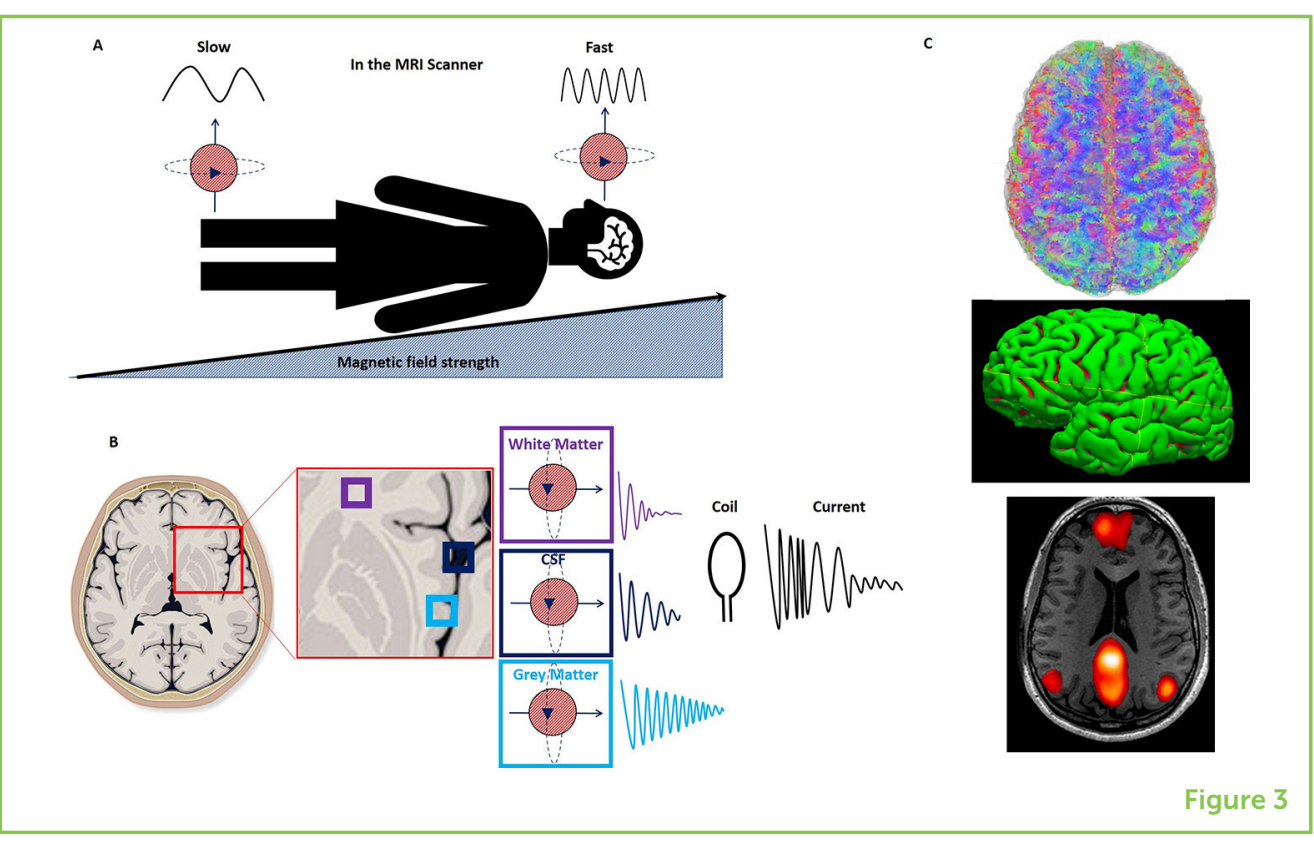

the needle rotate to point east if we place a small bar magnet next to the compass. This is similar to the way the protons behave when we turn on the RF pulse.

If the whole body is full of hydrogen "up" protons all spinning at the same precessing frequency in the $\mathrm{B0}$, how do we target just the ones in the brain to investigate mental health? We use the fact that the precessional frequency of the protons is dependant on the magnetic field strength. We apply a second magnetic field, B1 that varies across the body. In the example shown in Figure 3A, hydrogen protons in the head will then be spinning faster than those in the chest, stomach and feet. Then, we tune the RF pulse to the precessing frequency of the hydrogen protons in the head. The RF pulse will then only be resonant with the protons in the brain. Therefore, only the protons in the brain will absorb energy from the RF pulse and be flipped away from the BO field. We can obviously tune our RF pulse to be resonant with protons in other parts of the body, like the feet, if we were interested in imaging the feet!

\section{HOW DO WE GET AN IMAGE FROM THESE SPINNING PROTONS?}

So how do we get an image from these spinning, flipped hydrogen protons in the brain? When the RF pulse is turned off, the protons flip back and realign along the main magnetic field, BO. If we think of our compass again, when we move our small bar magnet away, the needle will rotate from east to north and align with the Earth's magnetic field once more. As the protons flip back and realign with B0, they give off energy. 
FOURIER

\section{TRANSFORM}

A mathematical calculation that is used to change the electrical current in a coil into an image.
Different tissues in the body give off different amounts of energy. To measure this emitted energy, we require some special equipment (called a coil) that is placed around the body part we are imaging (Figure 3B). The coil acts as an antenna and detects the released energy as an electrical current. The electrical current is transformed, via a computer, using a mathematical calculation called a Fourier transformation. Because protons in the different kinds of tissues in the brain, such as gray matter, white matter and blood, all give off different amounts of energy, the result of the transformed energy is a highly detailed image of the tissue inside the brain.

\section{CONCLUSION}

We have now described how we use MRI to generate and measure signal from water molecules in the body. But as well as providing images of the inside of our bodies, MRI can also be used to answer many different questions about the makeup of the brain and how it functions. From the MRI images, we can investigate not only the structure and chemical makeup of the brain, but also how our mind's network is connected and how different regions of the brain communicate with each other (Figure 3C). In this manner neuroscientists can investigate how the mind's network is different in health and mental health disorders. By understanding how mental health disease changes the brain we can begin to develop treatment for these disorders.

SUBMITTED: 27 September 2018; ACCEPTED: 04 February 2019; PUBLISHED ONLINE: 01 March 2019.

EDITED BY: Daniel F. Hermens, Sunshine Coast Mind and Neuroscience Thompson Institute, University of the Sunshine Coast, Australia

CITATION: Broadhouse KM (2019) The Physics of MRI and How We Use It to Reveal the Mysteries of the Mind. Front. Young Minds 7:23. doi: 10.3389/frym.2019.00023

CONFLICT OF INTEREST STATEMENT: The author declares that the research was conducted in the absence of any commercial or financial relationships that could be construed as a potential conflict of interest.

COPYRIGHT @ 2019 Broadhouse. This is an open-access article distributed under the terms of the Creative Commons Attribution License (CC BY). The use, distribution or reproduction in other forums is permitted, provided the original author(s) and the copyright owner(s) are credited and that the original publication in this journal is cited, in accordance with accepted academic practice. No use, distribution or reproduction is permitted which does not comply with these terms. 


\section{YOUNG REVIEWERS}

\section{MATTHEW FLINDERS ANGLICAN COLLEGE, AGES: 14-15}

Matthew Flinders Anglican College young reviewers are keen budding scientists who enjoy taking on challenges. They are a collaborative bunch of young minds, with shared interests in science, music, and sport. This group of young reviewers thoroughly enjoy being part of Frontiers for Young Minds and are excited to be involved in how science is being communicated and shaped.

\section{AUTHOR}

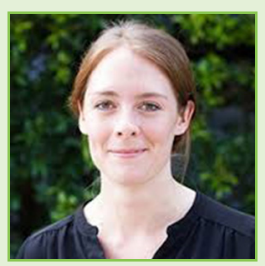

\section{KATHRYN MARY BROADHOUSE}

I decided I wanted to study Science and more specifically Physics at high school as I loved to learn how things and the universe work. When deciding my career, it was really important for me to be doing what I love, but also feel my work was meaningful and helping society. I therefore decided to specialize in medical imaging as this field combines a lot of the fundamental principles of physics to investigate and understand disorders and disease. *kathryn.broadhouse@usc.edu.au 


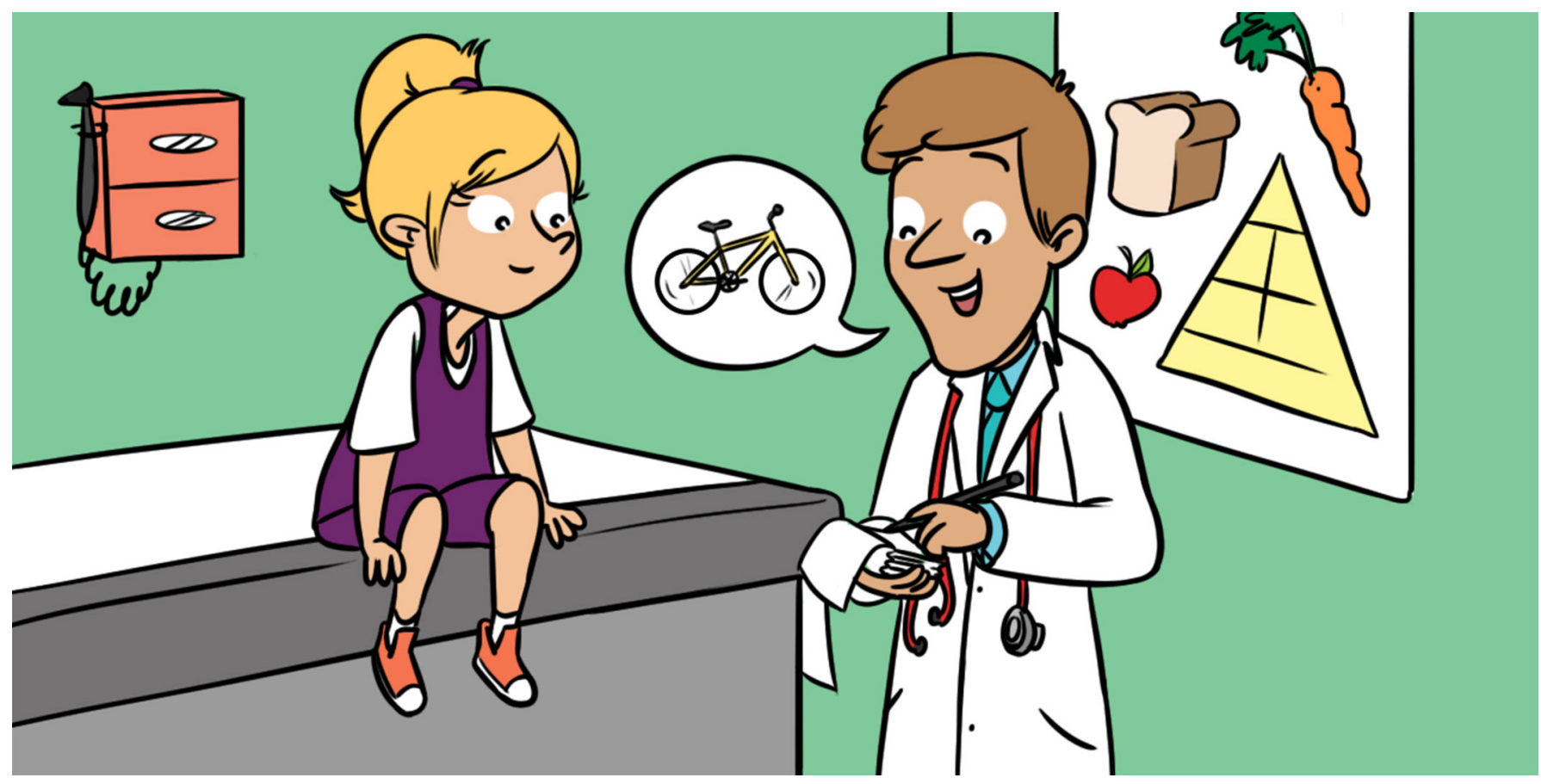

\section{MUSCLING UP ON MENTAL ILLNESS: HOW EXERCISE CAN HELP BOTH BODY AND MIND}

\section{Grace McKeon ${ }^{1}$ and Simon Rosenbaum ${ }^{1,2 *}$}

1 School of Psychiatry, University of New South Wales, Sydney, NSW, Australia

Black Dog Institute, Sydney, NSW, Australia

YOUNG REVIEWERS:

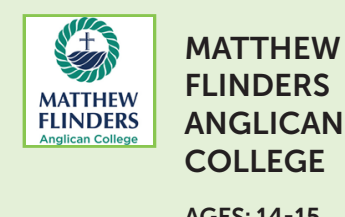

We know that regular exercise is important for maintaining a healthy body and for reducing the risk of developing chronic diseases, like heart disease and diabetes. Interestingly, the importance of exercise in maintaining a healthy mind is also becoming more and more clear. Exercise is now being prescribed by doctors as a part of treatment for a range of mental illnesses, including depression and anxiety. While scientists do not fully understand how exercise can help improve our mood, we know enough about the positive benefits of exercise to suggest that everyone living with mental illness should have access to tailored exercise programs as part of their recovery.

\section{EXERCISE}

You have heard it all before; get off your phone, stop watching TV, and go play outside, you couch potato! Are your parents and teachers just wasting their breath, or is there actually some science behind 


\section{EXERCISE}

Structured subset of physical activity that is planned and deliberate.

\section{MENTAL HEALTH}

Someones psychological and emotional wellbeing.

\section{MENTAL ILLNESS}

A group of illnesses that affects the mind for example, depression and anxiety. this advice? Let us take a look at some of the exciting research on how exercise can improve both physical and mental health.

How do you feel when you exercise regularly? Do you feel stronger? Fitter? More flexible? Exercise is known to help improve your cardiovascular system (your heart and lungs), to help you develop healthy bones, muscles, and joints, and help you maintain a healthy weight. Exercise has also been shown to help prevent and manage several chronic diseases, such as diabetes and heart disease.

Those are the benefits of exercise that you have probably already heard of. But how does your mind feel after you exercise? Do you feel happier? Can you think more clearly? Do you find it easier to fall asleep? Have a think about it and we will come back to this.

\section{WHAT IS MENTAL ILLNESS?}

Just like our bodies can get sick from time to time (like when we have a sore throat), so too can parts of our brain that control how we feel. This type of illness is called mental illness. Just like the phrase "cardiovascular disease" is used to describe a group of diseases that affect the heart, you can think of mental illness as broad term used to describe diseases that affect the mind. Mental illness includes a range of conditions you might have heard of, including depression and anxiety.

Everybody experiences a range of feelings that come and go; nervous, happy, lonely, excited, or angry. Sometimes the bad feelings do not go away and can start to impact important parts of our lives, such as the ability to perform at school or at work. Because we cannot see mental illness in quite the same way that we see physical illness or injury (like a broken leg), people sometimes find mental illness difficult to talk about. Even though we cannot "see" mental illness in the same way we can see a broken leg, it is important to remember that, just like a broken bone, with the right treatment and support, people can recover from a mental illness and live happy, healthy lives.

Mental illness is common and in Australia and affects around one in five people in any 1 year and $45 \%$ of the population at some point during their lifetime. Unlike many other health conditions, such as heart disease or arthritis, the risk of developing a mental illness does not increase with age. In fact, the first onset of a mental illness typically occurs in childhood or adolescence, with half of all cases of mental illness starting by the age of 14 and three quarters by age 24 [1]. It is estimated that $13.9 \%$ of children aged $4-17$ experience a mental illness [2]. 
PHYSICAL ACTIVITY

Any bodily movement produced by skeletal muscles that requires energy expenditure.
Given how many people experience mental illness, finding new ways of treating and preventing mental illness is extremely important.

It is also important to understand the difference between mental health and mental illness. You do not have to have a diagnosed mental illness to experience poor mental health. For example, the diagram below shows how mental health and mental illness can be separate.

Just like physical illnesses, people experiencing mental illness often find it harder to engage in exercise and, on average, spend more time sedentary (sitting or lying down), which we know is bad for our health. Think about when you have felt upset or down. Did you find it harder to find the motivation to do things like socialize or walk the dog? Even in the general population, motivation to exercise is low, with only $35 \%$ of the population getting the recommended amount of physical activity. So, it is not surprising that people with mental illness often even less likely to be active.

Think of it like this, our mental health and our physical health are connected. It can be difficult to have one without the other. Often, someone experiencing mental illness will also experience poor physical health, and poor physical health can in turn be associated with poor mental health.

\section{EXERCISE AS A TREATMENT FOR MENTAL ILLNESS}

We now know that exercise can be a really important part of care for people living with short- and long-term mental illness [3]. Exercise can improve mood and reduce symptoms of mental illness, including depression and anxiety. Exercise can also improve sleep quality, increase energy levels and reduce stress. Exercise has also been shown to increase self-confidence and improve both memory and concentration. Plus, exercise offers all these benefits without the risk of serious side-effects. It has been said that, if exercise were a pill, it would be prescribed to every patient by every doctor.

The benefits of exercise are "transdiagnostic," meaning that regardless of which mental illness someone may be experiencing, everyone can still gain some benefits from exercise. The benefits may differ a little depending on the symptoms experienced. For example, for someone with depression, exercise may help to improve sleep quality or help provide motivation to get out of bed, while for someone experiencing anxiety symptoms, exercise may act as a distraction from constant worry. 


\section{HOW CAN EXERCISE HELP?}

The mechanisms by which exercise reduces the symptoms of mental illness are not fully understood. We do know that exercise may provide a sense of enjoyment and fulfillment. Exercise can enhance self-efficacy (belief in our own abilities) and self-esteem (how we feel about ourselves) by helping us master new skills. Exercise can also be a great opportunity to make friends, whether it is in a dance class or on a soccer team.

In terms of the biological mechanisms, exercise has been shown to cause changes in certain chemicals called endorphins. Endorphins are the "feel good" chemical messengers that help relieve pain and stress during exercise. Exercise also stimulates the release of other chemicals called dopamine, norepinephrine, and serotonin. Sounds fancy but what does that mean? Well, these brain chemicals play an important part in regulating your mood. In fact, they are the same chemicals that are targeted by medications for mental illness. Exercise also helps to reduce the levels of a stress hormone called cortisol, so that we feel less stressed out.

Another important chemical is brain-derived neurotrophic factor, or BDNF. Think of it like "a fertilizer for your brain." BDNF is a protein in your brain that helps to maintain the life of your brain cells and helps you to grow new ones. Low levels of BDNF have been seen in people with mental illness like depression and anxiety. What is the good news? Exercise can also increase the brain's BDNF levels, which helps improve brain function, mood stability and general well-being [4]. Is there anything exercise cannot do?

Finally, exercise can also be used as a form of exposure therapy. Think about the feelings you experience when you feel stressed. Your body tenses, your heart races, you sweat, you become short of breath. Interestingly, these are the same feelings you can experience when you work up a sweat exercising. Exercise is therefore another way to expose people to anxiety symptoms, but in a safe and controlled manner that can help people become less sensitive to these symptoms and help with recovery from anxiety.

\section{SO, WHAT NOW?}

Knowing all these benefits is good, but if we do not change the way we treat mental illness to ensure that exercise is included as a part of treatment, and then the science alone is unlikely to help anyone. While many countries now include exercise as part of mental illness 
Figure 1

Mental health continuum. Mental health and mental illness are two distinct things.

For example, someone with a diagnosed mental illness may be recovering well and experiencing positive mental health, while someone with no diagnosable mental illness may be experiencing poor mental health at any one point in time.

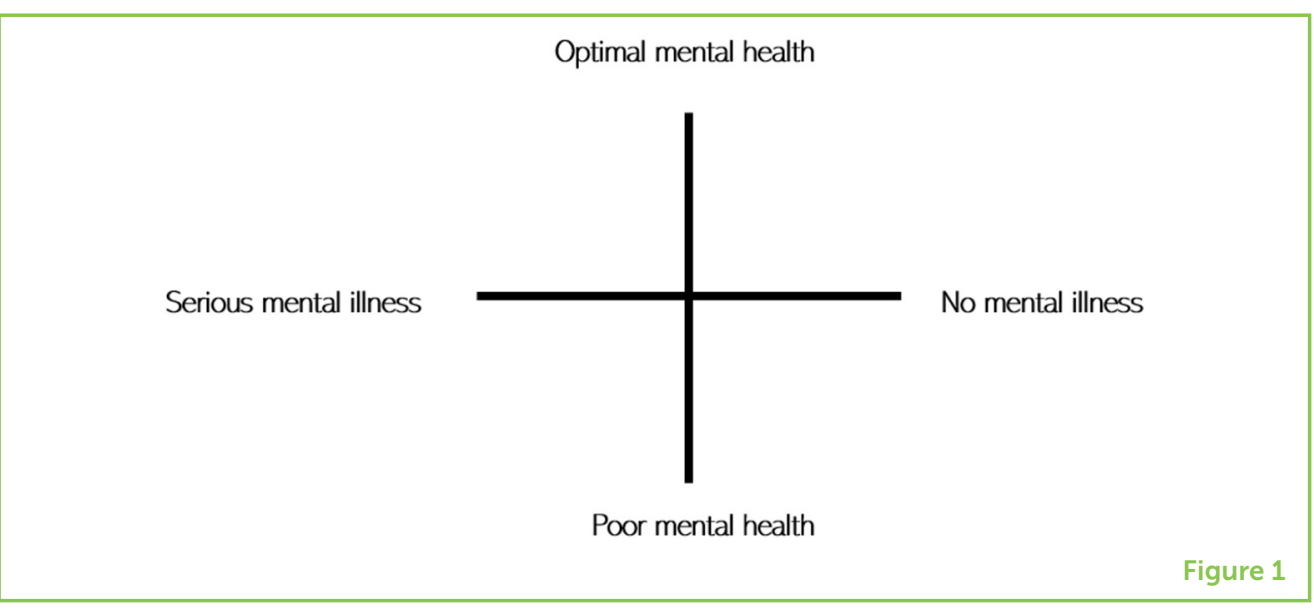

treatment, we still have a long way to go in terms of breaking down the divide between physical and mental health care. While exercise is not a replacement for medication or other treatments, it can clearly be an important and useful part of the treatment of mental illness.

We have spoken a lot about the benefits of exercise for people experiencing mental illness, but the thing about exercise is it can make you feel better even if you are already feeling okay. Think back to Figure 1. Everyone finds themselves somewhere on the mental health-mental illness continuum, and it is important to know you do not need to have a mental illness to experience the benefits of exercise. One large study combining data from all around the world showed that exercising can reduce your chances of developing depression by up to $17 \%$ [5]!

That being said, how much exercise should you be doing and what type is best? The Australian guidelines recommend that 5-12 years-old need 60 min of moderate to vigorous physical activity every day. Unfortunately, only one third of children meet these recommendations and it is even worse for adults. If you are not currently meeting these guidelines, increasing your activity gradually is the most achievable way. Even one exercise session a week can have great benefits for your mental and physical health. As we have said above, there are many types of exercise that can provide mental health benefits, not just running on a treadmill or lifting weights. You might prefer chasing friends, riding a bike, shooting basketball hoops, or dancing. Finding a type of exercise that you enjoy is critical. The benefits of exercise can occur regardless of the type of exercise.

Childhood through young adulthood is a really important time for our development and it lays the foundation for the rest of our lives, both physically and mentally. Think for a moment about your school PE classes. Is the thought enough to make you shudder? A new study found that the way we feel during gym classes at school can shape the way we feel about 
exercise in the future and whether we choose to be physically active [6]. There are many reasons why so many people are inactive, but most behavioral scientists agree that our attitudes about exercise play a defining role in whether or not we are physically active. If we expect exercise to be fun and enjoyable, often we will exercise. If we do not think exercise will be enjoyable, we would not. Simple as that. Therefore, establishing healthy habits and positive attitudes toward exercise at a young age is important. So, if you do not like PE class, it is about finding what you do enjoy and doing it regularly. Remember, our bodies are made to move. So, go on! Stop reading this boring old paper, grab a friend, and get moving.

\section{REFERENCES}

1. Kessler, R. C., Berglund, P., Demler, O., Jin, R., Merikangas, K. R., and Walters, E. E. 2005. Lifetime prevalence and age-of-onset distributions of DSM-IV disorders in the National Comorbidity Survey Replication. Arch. Gen. Psychiatry 62:593-602. doi: 10.1001/archpsyc.62.6.593

2. The Mental Health of Children and Adolescents. 2015. Report on the Second Australian Child and Adolescent Survey of Mental Health and Wellbeing. Available online at: www.health.gov.au

3. Rosenbaum, S., Tiedemann, A., Sherrington, C., Curtis, J., and Ward, P. B. 2014. Physical activity interventions for people with mental illness: a systematic review and meta-analysis. J. Clin. Psychiatry 75:964-74. doi: 10.4088/JCP.13r08765

4. Schuch, F. B., Deslandes, A. C., Stubbs, B., Gosmann, N. P., Silva, C. T., and Fleck, M. P. 2016. Neurobiological effects of exercise on major depressive disorder: a systematic review. Neurosci. Biobehav. Rev. 61:1-11. doi: 10.1016/j. neubiorev.2015.11.012

5. Schuch, F. B., Vancampfort, D., Firth, J., Rosenbaum, S., Ward, P. B., Silva, E. S., et al. 2018. Physical activity and incident depression: a meta-analysis of prospective cohort studies. Am. J. Psychiatry 175:631-48. doi: 10.1176/appi. ajp.2018.17111194

6. Ladwig, M. A., Vazou, S., and Ekkekakis, P. 2018. "My best memory is when i was done with it": PE memories are associated with adult sedentary behavior. Transl. J. Am. Coll. Sports Med. 3:119-29. doi: 10.1249/TJX.0000000000000067

SUBMITTED: 24 September 2018; ACCEPTED: 15 February 2019; PUBLISHED ONLINE: 11 March 2019.

EDITED BY: Daniel F. Hermens, University of the Sunshine Coast, Australia

CITATION: McKeon G and Rosenbaum S (2019) Muscling Up on Mental Illness: How Exercise Can Help Both Body and Mind. Front. Young Minds 7:35. doi: 10.3389/ frym.2019.00035 
CONFLICT OF INTEREST STATEMENT: The authors declare that the research was conducted in the absence of any commercial or financial relationships that could be construed as a potential conflict of interest.

COPYRIGHT (c) 2019 McKeon and Rosenbaum. This is an open-access article distributed under the terms of the Creative Commons Attribution License (CC BY). The use, distribution or reproduction in other forums is permitted, provided the original author(s) and the copyright owner(s) are credited and that the original publication in this journal is cited, in accordance with accepted academic practice. No use, distribution or reproduction is permitted which does not comply with these terms.

\section{YOUNG REVIEWERS}
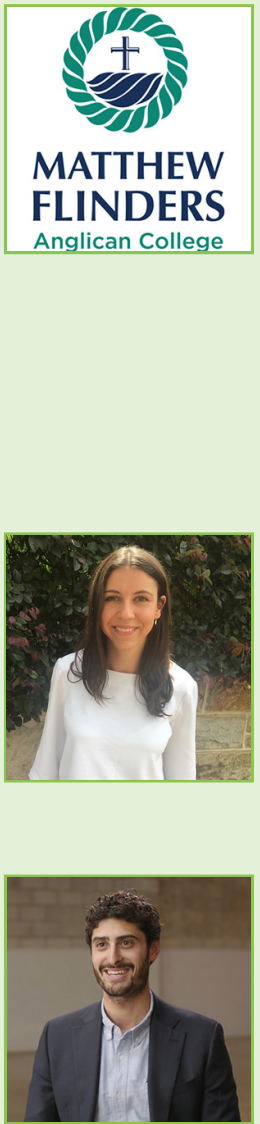

\section{MATTHEW FLINDERS ANGLICAN COLLEGE, AGES: 14-15}

Matthew Flinders Anglican College young reviewers are keen budding scientists who enjoy taking on challenges. They are a collaborative bunch of young minds, with shared interests in science, music, and sport. This group of young reviewers thoroughly enjoys being part of Frontiers for Young Minds and is excited to be involved in how science is being communicated and shaped.

\section{AUTHORS}

\section{GRACE MCKEON}

I am an Exercise Physiologist and Researcher at the University of New South Wales in Sydney Australia. My research looks at the benefits of physical activity on our mental health and how we can implement this in the real world. Outside of work, I love playing team sports and being outdoors.

\section{SIMON ROSENBAUM}

I am a Senior Research Fellow in the School of Psychiatry, UNSW Sydney and the Black Dog Institute. My research looks at the impact of physical activity on symptoms of mental illness and the use of exercise as a part of the standard care within mental health settings. I enjoy cycling, kayaking, rock climbing, and generally any type of physical activity, ideally outside. *s.rosenbaum@unsw.edu.au 


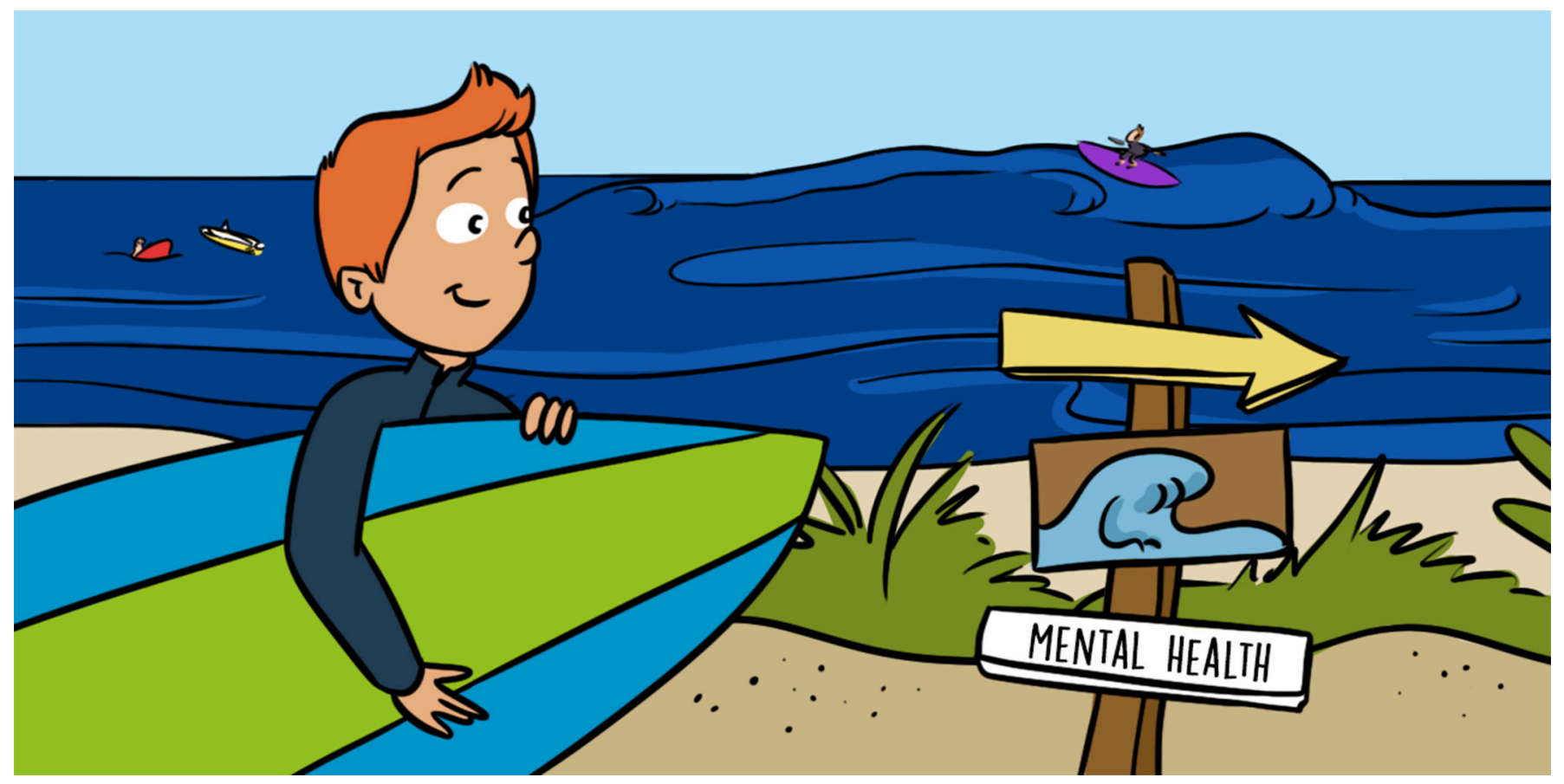

\section{HOW SURFING COULD BE A TREATMENT FOR MENTAL ILLNESS}

\section{Bryan D. Peck* and Jim Lagopoulos}

The Sunshine Coast Mind and Neuroscience Thompson Institute, University of the Sunshine Coast, Maroochydore, QLD, Australia

\section{YOUNG REVIEWERS:} MATTHEW FLINDERS ANGLICAN COLLEGE AGE: $14-15$
When we are mentally or physically unwell we can take medication to help with the symptoms we are experiencing. When we are mentally unwell we can also talk to someone about what is going on. Sometimes medication and talking work, and sometimes not. What if we could also do an activity that improves both the mental and physical symptoms of a mental illness? What if it was an activity that you would jump out of bed to do, because it is so much fun? What if, along with being fun, the activity, also helps the areas of the brain that are linked with some mental illnesses? Surfing, as a therapy, has shown positive effects on mental health, but what impact might it have on the brain of someone with post-traumatic stress disorder (PTSD)?

\section{WHAT IS MENTAL ILLNESS?}

A mental illness is a medical condition that affects the brain, resulting in changes in a person's thoughts, feelings, and behavior. Like many 
POST-TRAUMATIC STRESS DISORDER

A mental illness that can develop in people who have been through a traumatic event that threatened their life or safety.

\section{COGNITIVE}

FUNCTION

Mental processes that allow us to carry out important daily tasks, such as memory, attention, and problem solving.

\section{FIGHT-OR-FLIGHT}

A fear reaction of the brain and body in response to a threat, in which the body prepares us to either stay and fight the danger or run away.

AMYGDALA

("A-MIG-DA-LA")

A part of the brain important for emotional responses, regulation of fear and aggression, and the fight-or-flight response.

HIPPOCAMPUS ("HIPP-O-CAMP-US")

Responsible for learning and memory, as well as switching off the amygdala when there is no danger or threat.

\section{PREFRONTAL} CORTEX

An area of the brain that has a role in inhibiting the fight-or-flight response. physical illnesses, mental illness affects a person's ability to live their normal daily life. Sometimes, mental illness can make it difficult to go to work, to study, to get out of the house, or to catch up with friends and family. Some of the more common mental illnesses are anxiety disorders, clinical depression, and post-traumatic stress disorder (PTSD). Anxiety often involves problems with the fear response-this response is too elevated and occurs too often. Depression usually involves having low mood, loss of interest in activities, and low motivation for a long period of time. PTSD is another common mental illness and is the focus of this paper.

\section{WHAT IS POST-TRAUMATIC STRESS DISORDER?}

As the name suggests, post-traumatic stress disorder (PTSD) is a stress-based health condition that typically occurs after someone experiences a traumatic event. People can get PTSD after experiencing a trauma themselves (e.g., a natural disaster, accident, military combat), or by witnessing a trauma happening to someone else (e.g., seeing someone else involved in a car accident). People with PTSD experience significant changes in cognitive functioning (their thinking skills, like attention, and memory), have difficulty regulating their emotions, experience overwhelming memories and dreams relating to the traumatic event, and show an elevated fight-or-flight response, which is a response to a stressful situation in which our bodies prepare us to either stay and fight the danger or to run away. People with PTSD can also experience other negative effects as a result of living with this mental illness. For example, people with PTSD are more likely to have cardiovascular disease and diabetes. They are less likely to have healthy diets, less likely to engage in physical activity, more likely to be obese and to smoke.

\section{PTSD AND THE BRAIN}

Scientists can examine the brain in two different ways: by looking at its structure and its function. That is, scientists can measure the size and shape of different parts of the brain (structure), or they may look at the activity within and between different parts of the brain (function). Research using different brain imaging techniques has revealed that people with PTSD often have changes to both the structure and function of the brain, compared with people without PTSD. Figure 1 shows the three parts of the brain that are often looked at when we investigate PTSD: (1) the amygdala (where emotions are processed), (2) the hippocampus (where memories are stored), and (3) the prefrontal cortex (where problem-solving happens). Changes in the structure of the amygdala have been associated with the constant re-experiencing of traumatic events, which is a key symptom of PTSD. Changes in the structure of the hippocampus are associated with difficulty learning and remembering that non-threatening situations are safe. Changes in the structure of the prefrontal cortex are associated with a reduced ability to stop the fight or flight response. 
Figure 1

In PTSD, certain areas of the brain, such as the amygdala, show greater activity (up arrows) compared with healthy brains, whereas other areas, such as the prefrontal cortex and the hippocampus show reduced activity (down arrows).

\section{ADJUNCTIVE}

("AD-JUNC-T-IV")

A thing added to something else. In this case, an adjunctive therapy is a type of therapy added to traditional therapies such as medications and talk therapy.

ADVENTURE-BASED PHYSICAL ACTIVITY

Adventure-based physical activities are commonly performed in a natural setting, require high physical intensity, and include elements of risk and mental commitment.

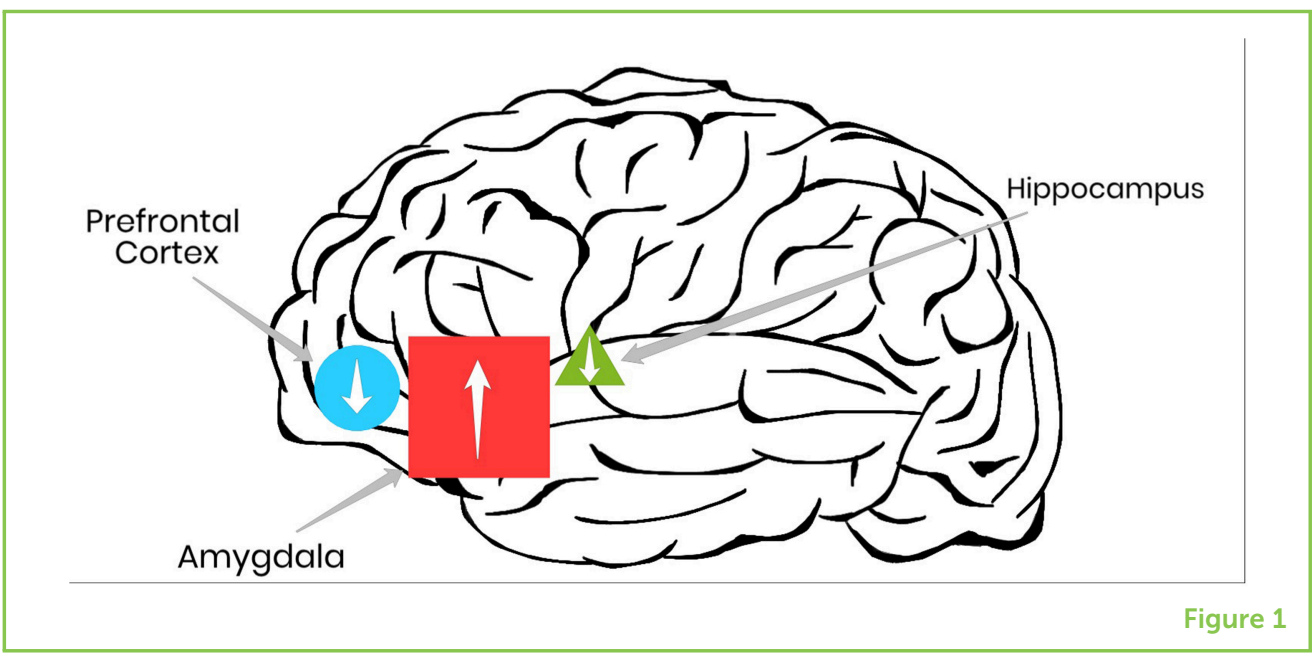

So, these three areas of the brain are often out of balance in people with PTSD.

\section{WHAT CAN WE DO FOR PATIENTS WITH PTSD?}

Current treatments for PTSD usually include medications and talk therapy. These treatments attempt to reduce symptoms, make changes in the brain, and ultimately improve quality of life. However, they do not always work, and when they do, they only work a little, or for a short time. Scientists are interested in finding and using other, better ways to treat mental illness. As such, there is increased interest in what are called adjunctive treatments, which are additional treatments that can be provided along with traditional treatments. Adjunctive treatments are particularly important for complex mental illnesses, such as PTSD.

\section{WHAT IF EXERCISE COULD HELP MENTAL ILLNESS?}

Physical activity is increasingly recognized as an important adjunctive therapy for mental illnesses. Physical activity therapies can include walking, swimming, yoga, or team and individual sports. We all know that physical activity is beneficial when it comes to preventing things like heart disease, high blood pressure, diabetes, and asthma. But you may not have known that physical activity is also linked to improvements in mental health (see Figure 2), including cognitive function (prefrontal cortex), memory (hippocampus), and stress management (amygdala). Physical activity has also been shown to reduce negative mood states, such as anger and depression, and improve positive mood states, such as feeling energized [1]. Adventure-based physical activity is an important alternative to the common sports and exercises. What are adventure-based physical activities and why are they important? They are activities that include an element of risk, they are performed in changing environments, they are of high intensity, and they require physical and mental 
Figure 2

Physical activity can help return brain functioning to healthy levels in the regions of the brain responsible for learning, problem solving, and responding to stress. For example, in the brains of people with mood disorders, physical activity can improve functioning in the prefrontal cortex and hippocampus (up arrows), and calm a hyperactive amygdala (down arrow).

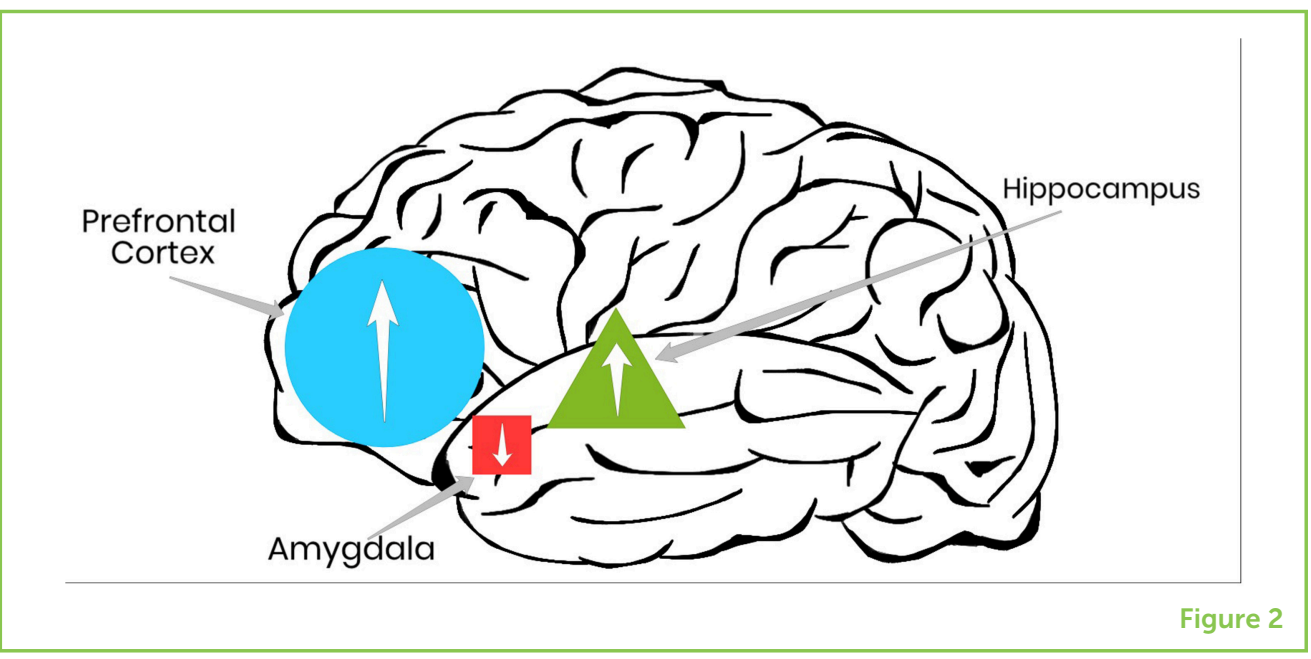

commitment. Some examples of adventure-based physical activities include rock climbing, hiking, snowboarding, and surfing. Surfing is an easily accessible activity performed by millions of people all over the world. Surfing as a therapy has been around for decades, and surfing therapy has been used on both kids with physical and mental disabilities and on combat veterans with PTSD and depression.

\section{SURFING AS A THERAPY FOR CHANGING THE BRAIN}

In order to understand the effects of surfing as an adjunctive treatment for PTSD, we will focus on three areas that highlight important elements of surfing that make it a good activity for making beneficial changes in the brain.

\section{Surfing is an Interaction with Nature}

Research shows us that exercising in natural environments can lead to positive effects on physical and mental health. In terms of mental health, scientists commonly look at the effects on a person's mood. Mood influences our feelings of satisfaction with life and our ability to deal with the ups and downs of the day, as well as the choices we make regarding our studies, work and relationships. Have you ever woken up "on the wrong side of the bed?" Mood disorders are also a major component of all mental illnesses. The brain is a complicated organ and the control of mood by the brain is no different. The prefrontal cortex, the amygdala, and the hippocampus are all involved in the regulation of mood. As it turns out, spending time in nature seems to lower stress levels, help the prefrontal cortex to focus, and lead to lower levels of mental fatigue. These effects are even greater if the physical activity is in the presence of water [2].

\section{Surfing Requires the Balance of Risk and Reward}

When we surf, we engage both mental and physical skills in a challenging environment that is constantly changing. Surfing requires 
commitment in order to manage the risk of falling off the surfboard, but is rewarded by the joy of riding the waves. In other areas of research, scientists know that those moments of feeling good involve activity in the reward pathways of the brain, including those in the prefrontal cortex. A chemical in the brain called dopamine plays a role in feeling good. In some mental illnesses, dopamine is thought to function improperly, leading to decreased desire for doing things that give us that good feeling. Can you imagine if hanging out with your friends did not feel good anymore? Surfers report the good feeling they get when catching a wave, and this feeling may help with managing their mental health, so that they have lower levels of depression and anxiety than the general population [3]. For people with PTSD, surfing could help with increasing their capacity for positive feelings like joy, and for managing mood in the face of a hyperactive fight-or-flight response.

\section{Surfing is a High Intensity Physical Activity}

Additionally, surfing is a physically demanding activity. The challenges associated with surfing are varied and include carrying the surfboard, high intensity paddling to catch a wave, push-ups to stand up on the surfboard, and balance. Research has shown that physical activity has a positive effect on multiple areas of the brain. Physical activity can change activity in the amygdala and hippocampus, which are both involved in our responses to threat and stress [4]. Physical activity can also increase the size of the hippocampus, improving its ability to let the amygdala know that there is no threat in safe situations. For example, one study showed that physical activity resulted in a $14 \%$ increase in the size of the hippocampus, after just 8 weeks of doing a cycling exercise [5].

\section{SURFING FOR PTSD}

Based on previous studies, we can predict that surfing as a therapy for PTSD will strengthen the hippocampus' ability to inhibit the fight-or-flight response and help to improve mood. Excitingly, we are looking to investigate the effects of surf therapy for people with PTSD. We are hoping to see changes in the structure and function of the three brain areas discussed in this paper. Hopefully, surf therapy will lead to improvements in the quality of life of people with PTSD.

\section{AUTHOR CONTRIBUTIONS}

BP wrote the manuscript. JL reviewed and edited.

\section{REFERENCES}

1. Basso, J. C., and Suzuki, W. A. 2017. The effects of acute exercise on mood, cognition, neurophysiology, and neurochemical pathways: a review. Brain Plast. 


\section{2:127-52. doi: 10.3233/BPL-160040}

2. Barton, J., and Pretty, J. 2010. What is the best dose of nature and green exercise for improving mental health? A multi-study analysis. Environ. Sci. Technol. 44:3947-55. doi: 10.1021/es903183r

3. Levin, B. J., and Taylor, J. 2011. Depression, anxiety, and coping in surfers. J. Clin. Sport Psychol. 5:148-65. doi: 10.1123/jcsp.5.2.148

4. Zschucke, E., Renneberg, B., Dimeo, F., Wustenberg, T., and Strohle, A. 2015. The stress-buffering effect of acute exercise: evidence for HPA axis negative feedback. Psychoneuroendocrinology 51:414-25. doi: 10.1016/j.psyneuen.2014.10.019

5. Pajonk, F.-G., Wobrock, T., Gruber, O., Scherk, H., Berner, D., Kaizl, I., et al. 2010. Hippocampal plasticity in response to exercise in schizophrenia. Arch. Gen. Psychiatry 67:133-43. doi: 10.1001/archgenpsychiatry.2009.193

SUBMITTED: 26 September 2018; ACCEPTED: 02 May 2019; PUBLISHED ONLINE: 24 May 2019.

EDITED BY: Daniel F. Hermens, University of the Sunshine Coast, Australia

CITATION: Peck BD and Lagopoulos J (2019) How Surfing Could be a Treatment for Mental Illness. Front. Young Minds 7:70. doi: 10.3389/frym.2019.00070

CONFLICT OF INTEREST STATEMENT: The authors declare that the research was conducted in the absence of any commercial or financial relationships that could be construed as a potential conflict of interest.

COPYRIGHT @ 2019 Peck and Lagopoulos. This is an open-access article distributed under the terms of the Creative Commons Attribution License (CC BY). The use, distribution or reproduction in other forums is permitted, provided the original author(s) and the copyright owner(s) are credited and that the original publication in this journal is cited, in accordance with accepted academic practice. No use, distribution or reproduction is permitted which does not comply with these terms.

\section{YOUNG REVIEWERS}

\section{MATTHEW FLINDERS ANGLICAN COLLEGE, AGE: 14-15}

Matthew Flinders Anglican College young reviewers are keen budding scientists who enjoy taking on challenges. They are a collaborative bunch of young minds, with shared interests in science, music, and sport. This group of young reviewers thoroughly enjoy being part of Frontiers for Young Minds and are excited to be involved in how science is being communicated and shaped. University of the Sunshine Coast, Australia. 


\section{AUTHORS}

\section{BRYAN D. PECK}

Bryan loves the water and being on and around the ocean. Bryan also really enjoys finding things out that help people with serious health conditions. Bryan is doing research into the effects of Adventure-based Physical Activity on the brains and lives of people who have Post-Traumatic Stress Disorder. Will there be a change in the brain? Will that change link with changes in mental illness and quality of life? We will soon see. *bryan. peck@research.usc.edu.au

\section{JIM LAGOPOULOS}

Prof Jim Lagopoulos is the director of the Sunshine Coast Mind and Neuroscience-Thompson Institute. Jim has extensive experience, with more than 20 years studying the brain. Jim seeks to make sure that the results of his research benefit people with mental illness. 


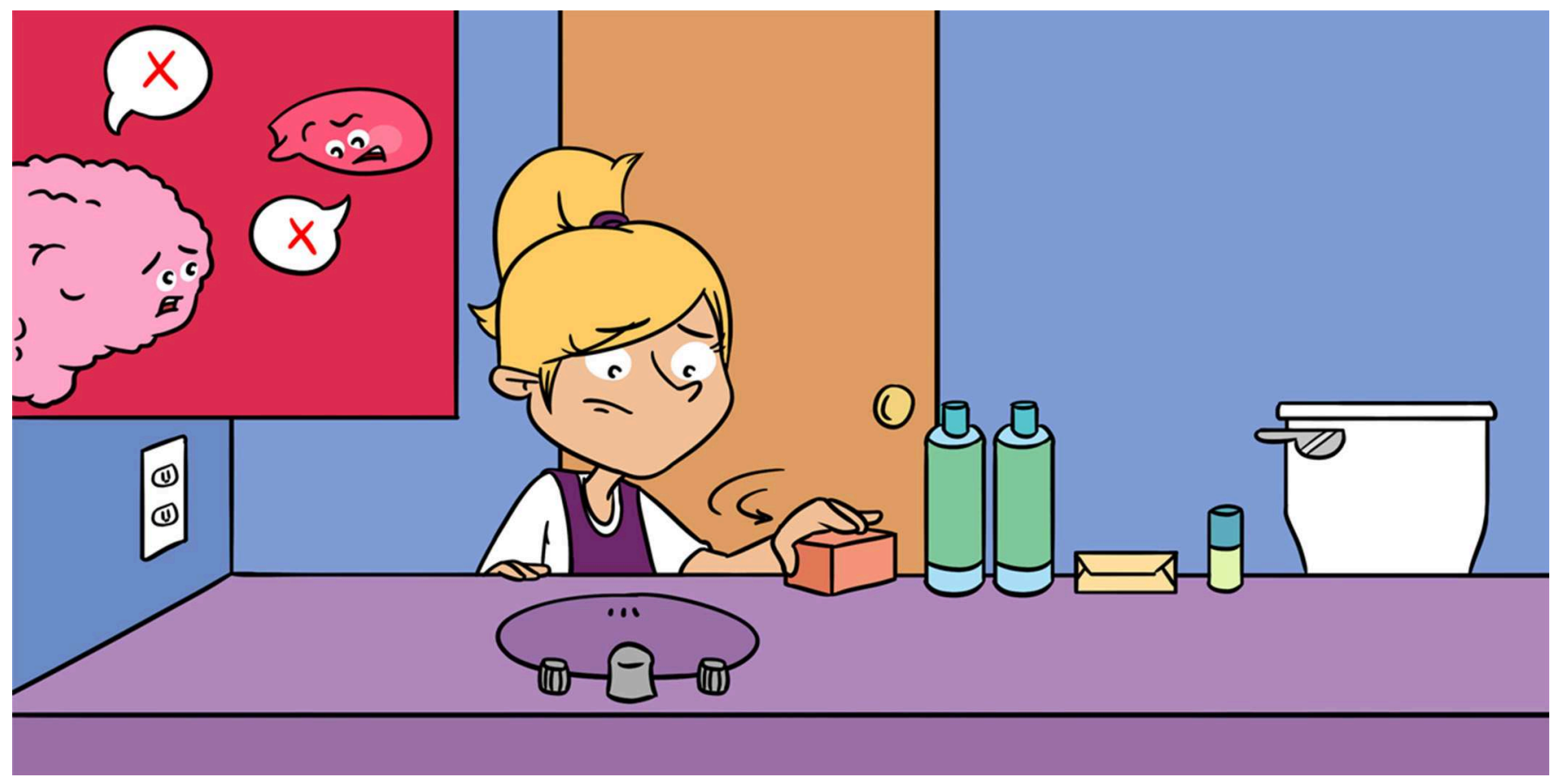

\section{WHAT IS OBSESSIVE COMPULSIVE DISORDER?}

\section{Pedro Morgado ${ }^{1,2,3 *}$ \\ ${ }^{1}$ Life and Health Sciences Research Institute (ICVS), School of Health Sciences, University of Minho, Braga, Portugal ${ }^{2}$ ICVS-3Bs PT Government Associate Laboratory, Braga, Portugal \\ ${ }^{3}$ Hospital de Braga, Braga, Portugal}

YOUNG REVIEWER:

SIENA COLLEGE AGE: 15
Obsessive-compulsive disorder is a brain disorder characterized by unwanted and repetitive thoughts that cause intense worry (called obsessions) and/or by repetitive behaviors that patients perform to try to relieve the suffering caused by obsessions (called compulsions). Treatments exist and include medication and psychotherapy (therapeutic conversations between a professional and the patient). New treatments using electromagnetic stimulation and/or a technique of real-time brain imaging are also being developed. In this article, we will describe the symptoms of this disorder, its causes, and the different treatments available. Learning about this disorder is very important, so that we will be able to identify and treat it appropriately.

\section{WHAT IS OBSESSIVE-COMPULSIVE DISORDER?}

Obsessive-compulsive disorder (OCD) is a brain disorder affecting $1-3 \%$ of the population worldwide. It affects men and women equally 


\section{OBSESSIONS}

Unwanted and repetitive thoughts, urges, or mental images that cause anxiety and suffering.

\section{COMPULSIONS}

Repetitive behaviors to reduce suffering provoked by obsessions. and it usually starts during childhood, adolescence, or early adulthood. It is uncommon for people to get OCD for the first time after the age of 30. As the name tells us, OCD is characterized by the presence of obsessions, compulsions, or both [1].

Obsessions are repetitive, unwanted, uncontrollable, and persistent thoughts (such as doubt about whether something they have done is good enough, or fear of germs), urges (such as saying something nasty), or mental images (such as violent scenes) that appear in the mind of the patient, causing intense anxiety and suffering. These worries just pop into the patient's head and can be hard to get rid of.

To reduce the suffering and distress caused by obsessions, the patient can be compelled to perform repetitive behaviors (called compulsions). Compulsions (also called rituals) can include checking and re-checking whether something is closed or locked, or washing and cleaning too much, or they can be mental acts, such as repeating a word or counting something. Patients feel driven to perform these compulsions in response to their obsessions.

It is important to know that everyone can experience obsessions and compulsions occasionally. Obsessions, such as the thought, "did I really lock the door to the house?," and compulsions, such checking and rechecking your answers when taking a test at school, are usually good things, because they improve our performance and reduce the chance of errors. To cross over into OCD, obsessive thoughts must occur for more than $1 \mathrm{~h}$ each day and/or interfere significantly with daily life.

\section{TYPES OF OBSESSIONS AND COMPULSIONS}

Obsessions and compulsions generally involve several common themes, which are summarized in Table 1.

\section{WHAT CAUSES OCD?}

OCD is a brain disorder caused by multiple factors that are not completely known nor understood. In some cases, OCD is genetic (inherited through the mother's or father's genes), but in other cases it is related to certain infections (in rare situations, some children develop obsessive symptoms after a severe throat infection, for example), traumatic events (such as threatening situations, abuse, or bullying), and/or chronic stress [2]. We already know that OCD is not caused by anything that the patient or his/her parents did "wrong."

The brain works like a computer, with multiple networks connecting brain regions that are responsible for different functions. We have 


\section{Table 1}

Examples of obsessions and compulsions.

\section{CORTEX}

The folded surface of brain.

\section{BASAL GANGLIA}

Group of nuclei located under the cerebral cortex.

\begin{tabular}{lll}
\multicolumn{1}{c}{ Category } & Examples of obsessions & Associated compulsions \\
\hline Contamination & $\begin{array}{l}\text { Feeling of being dirty } \\
\text { Fear of being contaminated }\end{array}$ & $\begin{array}{l}\text { Washing and cleaning rituals } \\
\text { Avoidance of } \\
\text { touching something } \\
\text { Doubt }\end{array}$ \\
Doubting if the door is locked & $\begin{array}{l}\text { Checking and re-checking if it } \\
\text { is locked }\end{array}$ \\
Symmetry & $\begin{array}{l}\text { The feeling that something has } \\
\text { to be arranged "just right" }\end{array}$ & $\begin{array}{l}\text { Putting things in just the right } \\
\text { order }\end{array}$ \\
Superstition & $\begin{array}{l}\text { Something is lucky or unlucky, } \\
\text { bad or good, safe or harmful }\end{array}$ & $\begin{array}{l}\text { Touching, tapping, or stepping } \\
\text { in an unusual way }\end{array}$ \\
Forbidden thoughts & $\begin{array}{l}\text { Repetitive thoughts about acting } \\
\text { inappropriately }\end{array}$ & $\begin{array}{l}\text { Avoiding situations out of fear } \\
\text { of acting inappropriately }\end{array}$ \\
\hline
\end{tabular}

Table 1

complex systems for every function. For example, one brain network is responsible for acquiring and managing the data that comes in from our senses, another is responsible for creating and managing our emotions, another is responsible for movements, and another is responsible for creating, managing and prioritizing our thoughts.

In OCD, the communication system between parts of the brain, namely the orbitofrontal cortex and the basal ganglia, is disrupted and the brain makes mistakes when processing and prioritizing information.

The orbitofrontal cortex is responsible for using information from the senses to make decisions, and anticipating the result of our life choices. In OCD, this region is hyperactivated and detects errors and dangers where there is not anything wrong.

The basal ganglia controls movements and thinking, and acts as a control system that filters and stops anxious thoughts. In OCD, the basal ganglia fail to control the errors and dangers wrongly identified by the orbitofrontal cortex, which makes the patient overwhelmed by his or her thoughts and actions (Figure 1).

\section{HOW IS OCD DIAGNOSED AND TREATED?}

Many people suffering from OCD recognize that their obsessions and compulsions are unreasonable, which makes them feel ashamed and embarrassed. The shame and embarrassment often stop some OCD patients from seeking treatment, which prolongs their suffering.

The diagnosis of OCD is done by doctors who can recognize the symptoms and signs of the disorder. The doctors diagnose OCD by asking specific questions. When the disease is identified, patients may feel relieved to know what is causing their suffering.

Treatments for OCD usually involve a combination of medication and psychotherapy. The medications most often used to treat OCD 
Figure 1

Brain regions affected in OCD. Studies suggest that communication between the front part of the brain (the orbitofrontal cortex) and a deeper structure of the brain (the basal ganglia) is disrupted in OCD.

\section{Figure 2}

The OCD cycle. Obsessions are intrusive thoughts or images that can be very disturbing. Because of the anxiety created by the obsession, compulsions are developed in order to relieve this anxiety. Antidepressants act by decreasing obsessions and their related anxiety, while psychotherapy (also called CBT or cognitive behavioral therapy) helps patients to learn how to resist to compulsions.

\section{SEROTONIN}

Chemical substance used to transmit messages between neurons

(neurotransmitter).
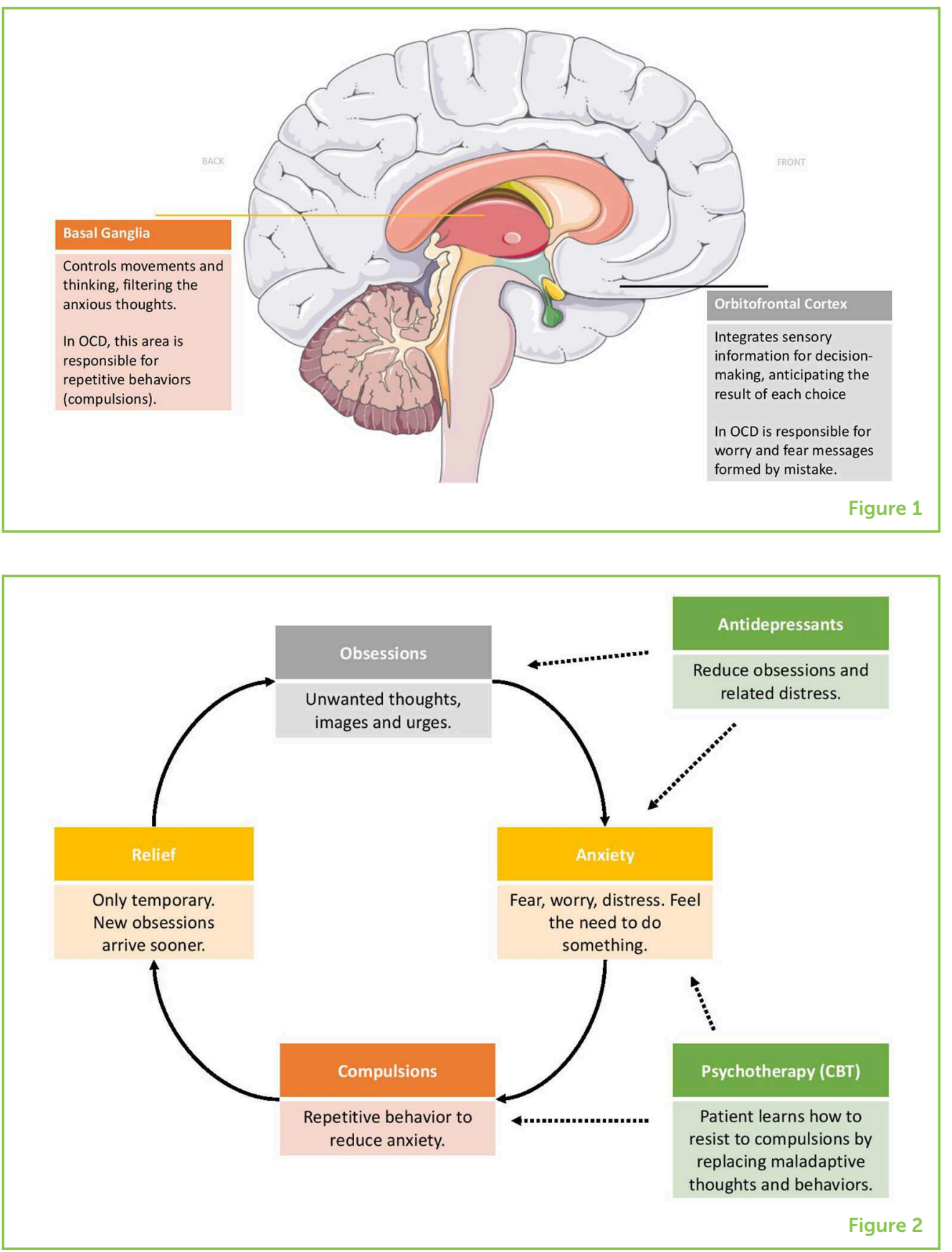

are called serotonin reuptake inhibitors (SRIs), which work to fix the hyperactivation of the orbitofrontal cortex and to reduce the anxiety caused by the obsessions (Figure 2).

Psychotherapy can also be effective in the treatment of OCD. Psychotherapy is a therapeutic conversation between a professional (a therapist, psychologist, or psychiatrist) and the patient that can help to identify, understand, and resolve problems. The most effective psychotherapy is called cognitive behavioral therapy (CBT), which focuses on identifying and replacing inappropriate thoughts and behaviors to help patients resist their compulsions. In therapy sessions, patients learn more about OCD and how it works. Because the 
rituals patients perform keep their OCD going strong, patients learn and practice ways to ignore worrisome thoughts and to face the fear caused by their obsessions. By avoiding compulsions, patients eventually learn to stop the cycle of OCD (Figure 2), allowing their brain networks to work in a healthier way again.

Some research groups are working to develop new ways to treat OCD. The new treatments being tested include the electromagnetic stimulation of specific brain regions (to enhance or reduce the activation of these regions), and feedback using real-time brain imaging to provide the patients with information about the activation of the brain regions involved in OCD, and new forms of psychotherapy, such as online psychotherapy or group psychotherapy (Figure 2).

\section{CONCLUSIONS}

OCD is a common disorder that affects young people. It is characterized by repetitive and unwanted thoughts, images, and urges that cause worry (obsessions) and by repetitive behaviors that are used to control the anxiety provoked by obsessions (compulsions). In OCD, there is a dysfunction in the communication system of the brain, which causes problems with information processing. Treatments for OCD are available and include medications and psychotherapy. New treatments are being developed to provide better ways of helping those suffering from OCD.

\section{ACKNOWLEDGMENTS}

Figure 1 was created using Servier Medical Art under Creative Commons Attribution 3.0 Unported License.

\section{REFERENCES}

1. Richter, P. M., and Ramos, R. 2018. Obsessive-compulsive disorder. Continuum (Minneap Minn). 24:828-44. doi: 10.1212/CON.0000000000000603

2. Morgado, P., Freitas, D., Bessa, J. M., Sousa, N., and Cerqueira, J. J. 2013. Perceived stress in obsessive-compulsive disorder is related with obsessive but not compulsive symptoms. Front. Psychiatry 4:21. doi: 10.3389/fpsyt.2013.00021

SUBMITTED: 24 April 2019; ACCEPTED: 20 November 2019;

PUBLISHED ONLINE: 09 December 2019.

EDITED BY: Daniel F. Hermens, Sunshine Coast Mind and Neuroscience Thompson Institute, University of the Sunshine Coast, Australia

CITATION: Morgado P (2019) What Is Obsessive Compulsive Disorder? Front. Young Minds 7:138. doi: 10.3389/frym.2019.00138 


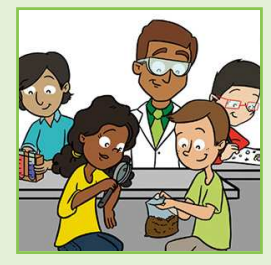

CONFLICT OF INTEREST: The author declares that the research was conducted in the absence of any commercial or financial relationships that could be construed as a potential conflict of interest.

COPYRIGHT @ 2019 Morgado. This is an open-access article distributed under the terms of the Creative Commons Attribution License (CC BY). The use, distribution or reproduction in other forums is permitted, provided the original author(s) and the copyright owner(s) are credited and that the original publication in this journal is cited, in accordance with accepted academic practice. No use, distribution or reproduction is permitted which does not comply with these terms.

\section{YOUNG REVIEWER}

\section{SIENA COLLEGE, AGE: 15}

We are high-school students at Siena College. We have a variety of interests and enjoy studying sciences and the humanities. We were pleased to contribute to this interesting article.

\section{AUTHOR}

\section{PEDRO MORGADO}

I am a Professor at the School of Medicine, University of Minho (Braga, Portugal) and a Psychiatrist at Hospital de Braga. Since early, I was fascinated by the human mind and wanted to understand how it works. As a researcher, I am interested in understanding how chronic stress affects our decisions and emotions, inducing disorders, such as OCD. When I am not working, I can be found spending time with partner, family, and friends. I like museums, running, reading, and traveling the world. You can follow my research activities (and other stuff) via Twitter: www.twitter.com/pedromorgado *pedromorgado@med.uminho.pt. 


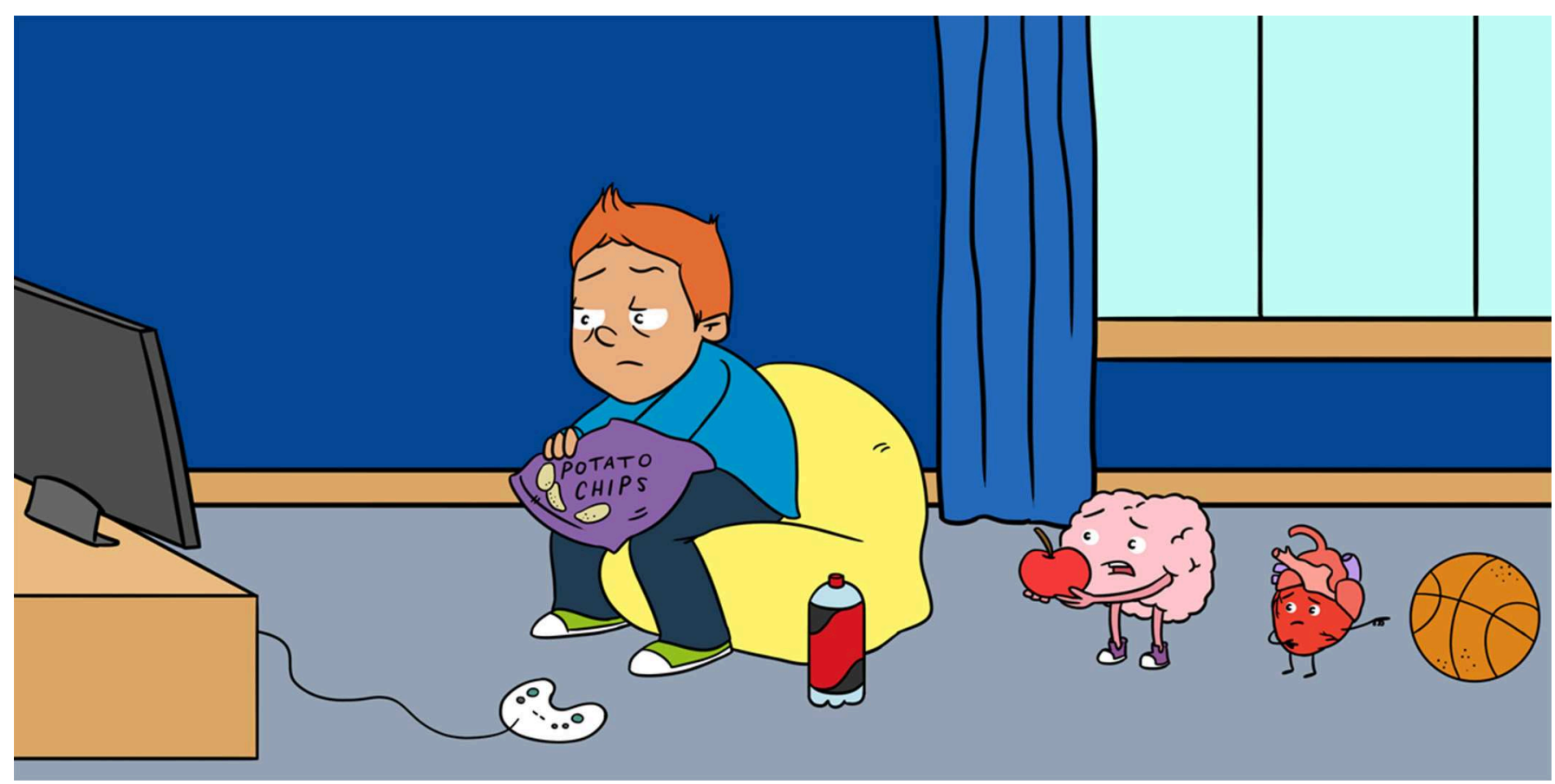

\title{
MIGHT LIFESTYLE CHOICES REDUCE THE RISK OF DEPRESSION?
}

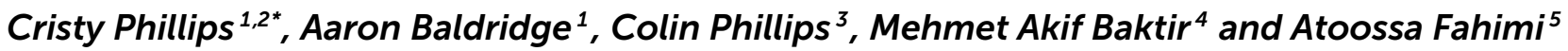 \\ ${ }^{1}$ Department of Physical Therapy, Arkansas State University, Jonesboro, AR, United States \\ ${ }^{2}$ University of Tennessee Health Science Center, Memphis, TN, United States \\ ${ }^{3}$ Department of Biology, Lyon College, Batesville, AR, United States \\ ${ }^{4}$ Department of Physiology, School of Medicine, Erciyes University, Kayseri, Turkey \\ ${ }^{5}$ Silverberry Genomics, San Francisco, CA, United States
}

YOUNG REVIEWER:

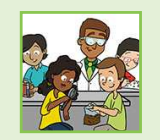

\section{EMILY}

AGE: 15

\section{DEPRESSION}

A mental illness that causes intense sadness and changes in the way a person thinks, feels, and behaves.
Depression is a common mental illness that affects millions of people worldwide. Depression is not sadness. The low mood in depression is more intense than the typical experience of sadness. It lasts over 2 weeks and interferes with daily activities. Too much stress can contribute to depression and other health problems. Stress does that by changing the balance of chemicals, hormones, and immune proteins. In this article, you will learn about new research on the connections between stress, inflammation, and depression. You will also learn how lifestyle choices can promote brain health, lower the bad effects of stress, and reduce the risk of depression.

Depression is a mental illness that impacts millions of people. It affects the way a person thinks, feels, and behaves. Depression is more intense than the experience of sadness. Important symptoms of depression include low mood, loss of pleasure, weight loss or gain, low energy, 
STRESS

A state where the body responds to mental, emotional, or physical threats.

INFLAMMATION

A state in the body in which the immune system responds to disturbances in the balance of body systems, injury, or infection. and feelings of hopelessness. These symptoms last over 2 weeks and interfere with a person's daily activities. Depression affects the depressed person, the person's family, and the community. In the United States, over 80 billion dollars a year is spent on depression. Most important, depression can be fatal, so it requires as much care as a serious physical illness.

We need to understand the causes of depression. This need has prompted decades of study. Research now shows that many factors contribute to depression. Of the known factors, stress is very important. Stress can cause depression over time [1]. Fortunately, lifestyle choices can reduce the ill effects of stress and depression. Let us consider factors that contribute to an increased risk for depression and decide if we can choose a path of health that reduces our risk of this illness.

\section{STRESS CAN CAUSE DEPRESSION}

Stress is usually a good thing, because it occurs when the brain perceives a threat. When that happens, the brain responds to the perceived threat by releasing stress hormones, such as cortisol. These hormones travel through the blood to the rest of the body, to help us respond to the threat [2]. For instance, under stress, heart rate increases, and our cells supply us with more energy.

After the threat ends, the stress response usually stops quickly. But not always. If the stress continues, then the stress response also continues. This disrupts the body's balance, because the body's stress shut-off mechanism stops working and the tissues become used to the stress hormones. The parts of the brain that control the stress response become damaged. The amygdala - the part of the brain that detects threats and makes us feel fear-grows in size and begins talking too much to the other brain regions. Negative brain talk then dominates. Sometimes, these chemical changes in the brain are related to inflammation caused by the stress.

\section{CONNECTING STRESS AND INFLAMMATION}

Inflammation is the immune system's first line of defense in dealing with threats. The immune system constantly monitors the brain and body for threats. The types of threats that the immune system is looking for include mental challenges, relationship challenges, injuries, irritations, diseases, or toxins. So usually, inflammation is another good thing. However, long-term stress can cause excessive inflammation. This happens because the continuing stress causes the immune system to produce pro-inflammatory proteins, which signal that there is a threat to the body, even when there is none. Trouble results if pro-inflammatory immune proteins stay active for 
NEUROTRANSMITTER

A chemical substance that conveys information from one neuron in the brain to another.

\section{NEUROGENESIS}

A process in certain parts of the brain where new neurons are formed to replace those that are injured. too long. Healthy cells, blood vessels, and tissues become damaged. The pro-inflammatory proteins also cause changes in the brain.

Evidence links pro-inflammatory immune proteins with depression. For one thing, depressed people have more pro-inflammatory proteins. Second, people who have been exposed to long-term stress often have both inflammation and depression. Third, people with inflammatory conditions often get depressed. Fourth, animal studies show that animals get depressed when given pro-inflammatory substances. They get better after being given anti-inflammatory medicines. All these pieces of evidence link inflammation to depression in certain people [3].

\section{A UNIQUE TYPE OF DEPRESSION RESULTS FROM STRESS AND INFLAMMATION}

Several studies support the idea that inflammation caused by stress creates a unique type of depression. Pro-inflammatory proteins cause an imbalance in chemicals in the brain (see Figure 1). These chemicals allow different kinds of "talk" to go on in the brain. Specialized chemicals, called neurotransmitters, can talk in the brain in different ways. Serotonin talks about eating, sleeping, learning, and feeling good. Dopamine talks about movement, reward, and motivation. Serotonin and dopamine talk together about well-being. Norepinephrine talks about threat and whether to fight or flee the threat. When the balance of these chemicals is disturbed, the message that results from their chatter shifts toward a negative bias. This negative bias can contribute to symptoms of depression.

Drugs for depression are called antidepressants. These drugs target neurotransmitters in an attempt to make their levels normal. The problem is that these drugs do not work for everyone. Many people who take antidepressants fail to get relief from their depression. For those who do benefit, the effects take weeks. The reason that antidepressants might not work well in all people may be connected to neurogenesis, which is the brain's process of making new neurons. Neurogenesis occurs in a part of the brain called the hippocampus. Some newly born neurons in the hippocampus start working to regulate stress, and these new neurons may help to decrease depression. However, people with stress, inflammation, and depression tend to have low levels of neurogenesis. As a result, damaged neurons are not replaced in the brain in an ongoing process. This may cause antidepressants to fail, because the brain requires both newly born neurons and restored levels of neurotransmitters to heal effectively [4]. 
Figure 1

Overview of the effects of stress on the brain and body. Stress affects the immune, nervous, and endocrine systems. Specifically, stress alters the release of pro-inflammatory proteins from cells in the immune system; in turn, pro-inflammatory proteins work on other systems.

Pro-inflammatory proteins alter neurotransmitter function in the brain and the release of stress hormones in the body. Also, stress directly alters the release of neurotransmitters in the brain. In the turn, neurotransmitter changes alter the function of immune proteins and the release of stress hormones. Finally, stress directly alters the release of stress hormones from glands in the endocrine system (or the adrenal glands which sit on the kidneys). In turn, the release of stress hormones then affects the function of neurotransmitters and immune system. Together, these direct and indirect changes in the brain and body cause symptoms of depression.

\section{LIFESTYLE FACTORS}

Modifiable choices that influence health and well-being.

\section{EXERCISE}

Activity that requires physical effort and is carried out to improve health.

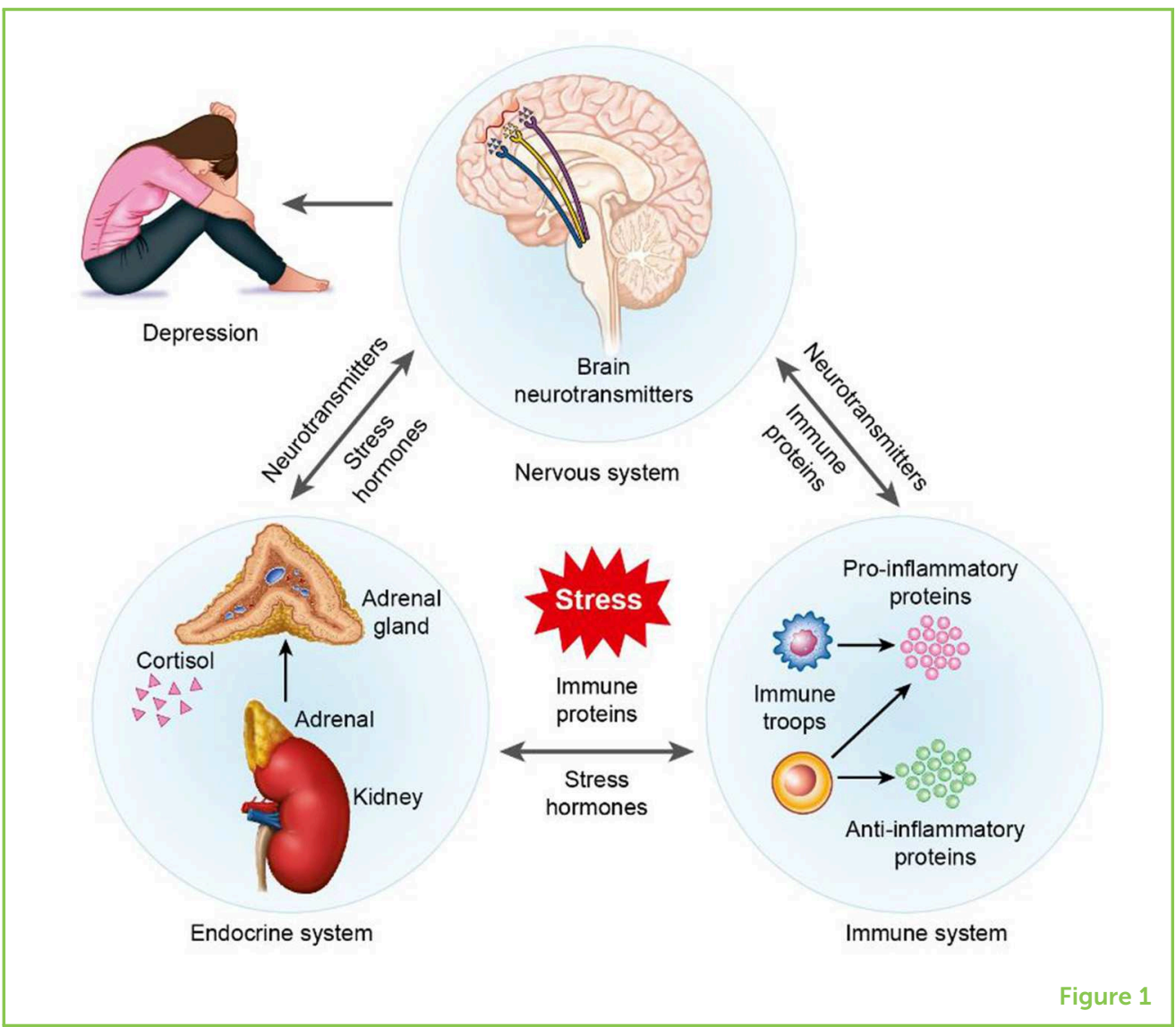

\section{REDUCING THE RISK FOR DEPRESSION THROUGH LIFESTYLE FACTORS}

Some people think that depression cannot be prevented. This is because many risk factors for depression are fixed, meaning they are genetic, environmental, and biological factors that are impossible or very difficult to change. Yet not all key factors are fixed. Many lifestyle factors can be modified [5].

Lifestyle factor choices, such as what we eat, how much sleep we get, and how much we exercise, can increase or decrease stress. These lifestyle factors can also have pro- or anti-inflammatory effects. So, depression might serve as a signal that we need to make better lifestyle choices. A balanced lifestyle that takes into account diet, exercise, and sleep reduces the bad effects of stress and inflammation on the body and the brain.

Eating correctly protects the brain. A healthy diet includes nutritious foods and limits calories, sugars, and saturated fats. According to the recommended guidelines, people ages 10-18 should consume $2,000-3,200$ calories daily. The exact number of calories that should be eaten depends on the person's sex and activity level. Yet, it is not just about calories. There is good evidence that some foods help the body and brain deal better with stress and inflammation and, in 
doing so, also reduce the risk of depression. For example, low-fat and low-sugar diets reduce inflammation and promote health. Also, a diet high in plant-based foods is important, because these foods contain anti-inflammatory compounds. This is an excellent reason to include plenty of fresh vegetables and fruits in our diets.

Exercise is also an important lifestyle factor choice, because it reduces the activity of the body's stress and inflammation systems. Exercise does this in part by reducing pro-inflammatory proteins and increasing anti-inflammatory proteins in the blood. Today, we can engage in many activities that are not very physical. These include watching TV, playing video games, and surfing the Internet. All these activities may be fun and valuable, but it is also very important to get daily physical exercise. Children and teens ages 6-17 should get 60 min of physical activity each day. Healthful and beneficial physical activities include playing baseball, soccer, and other team sports, as well as running, swimming, walking, hiking, and mowing the lawn. In fact, these activities include just about anything that gets us out of our chairs and moving. The great thing about exercise is that it makes both the body and the brain happy. That is why we need to make daily exercise a habit when we are young. We should also make regular exercise a lifelong goal. If we do that, we will enjoy health benefits throughout life. These benefits include reduced stress levels, reduced risk of excess inflammation, and reduced risk of becoming depressed.

Sleep is a third important lifestyle factor for brain and body health. Many people eat an appropriate diet and exercise regularly, but then they cancel the positive effects of those choices by sleeping only $4-5 \mathrm{~h}$ per night. Lack of sleep is a problem, because it causes the release of pro-inflammatory proteins and negatively changes hormone levels. These changes increase the risk of becoming depressed. Children and teens need plenty of sleep, because their bodies and brains are still growing. The recommended amount is $8-10 \mathrm{~h}$ of sleep each night. Without enough sleep, the brain does not work at peak efficiency. But, after adequate sleep, the brain is sharp and the body is ready for action.

\section{CONCLUSION}

Our healthy lifestyle choices can (1) build the brain's and body's protection against stress and inflammation, (2) lower the risk for depression, and (3) reduce the symptoms of depression in those who are already depressed. This knowledge suggests that we need to make choices that promote brain and body health. We also need to monitor ourselves to make sure we are consistently making healthy choices. When we make these good choices about diet, exercise, and sleep, we are better able to cope with illness when it strikes. We can also help those we love to improve their own health by serving as good examples. 


\section{REFERENCES}

1. Russo, S. J., Murrough, J. W., Han, M. H., Charney, D. S., and Nestler, E. J. 2012. Neurobiology of resilience. Nat. Neurosci. 15:1475-84. doi: 10.1038/nn.3234

2. Joels, M., and Baram, T. Z. 2009. The neuro-symphony of stress. Nat. Rev. Neurosci. 10:459-66. doi: 10.1038/nrn2632

3. Iwata, M., Ota, K. T., and Duman, R. S. 2013. The inflammasome: pathways linking psychological stress, depression, and systemic illnesses. Brain Behav. Immun. 31:105-14. doi: 10.1016/j.bbi.2012.12.008

4. Phillips, C., and Fahimi, A. 2018. Immune and neuroprotective effects of physical activity on the brain in eepression. Front. Neurosci. 12:498.

doi: 10.3389/fnins.2018.00498

5. Lopresti, A. L., Hood, S. D., and Drummond, P. D. 2013. A review of lifestyle factors that contribute to important pathways associated with major depression: diet, sleep and exercise. J. Affect. Disord. 148:12-27. doi: 10.1016/j.jad.2013.01.014

SUBMITTED: 28 November 2018; ACCEPTED: 20 November 2019; PUBLISHED ONLINE: 11 December 2019.

EDITED BY: Daniel F. Hermens, Sunshine Coast Mind and Neuroscience Thompson Institute, University of the Sunshine Coast, Australia

CITATION: Phillips C, Baldridge A, Phillips C, Baktir MA and Fahimi A (2019) Might Lifestyle Choices Reduce the Risk of Depression? Front. Young Minds 7:137. doi: 10.3389/frym.2019.00137

CONFLICT OF INTEREST: The authors declare that the research was conducted in the absence of any commercial or financial relationships that could be construed as a potential conflict of interest.

COPYRIGHT @ 2019 Phillips, Baldridge, Phillips, Baktir and Fahimi. This is an open-access article distributed under the terms of the Creative Commons Attribution License (CC BY). The use, distribution or reproduction in other forums is permitted, provided the original author(s) and the copyright owner(s) are credited and that the original publication in this journal is cited, in accordance with accepted academic practice. No use, distribution or reproduction is permitted which does not comply with these terms.

\section{YOUNG REVIEWER}

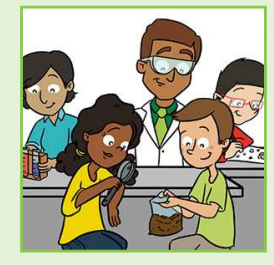

\section{EMILY, AGE: 15}

We are high-school students at Siena College. We have a variety of interests and enjoy studying sciences and the humanities. We were pleased to contribute to this interesting article. 

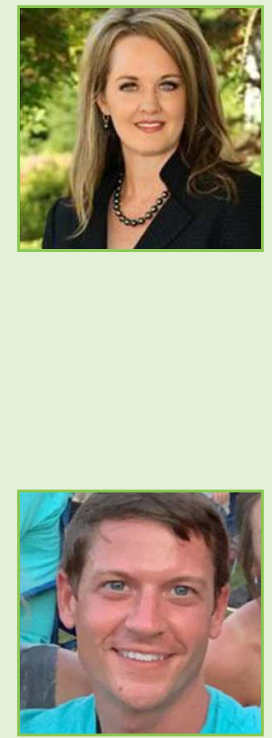

\section{AUTHORS}

\section{CRISTY PHILLIPS}

I am an Associate Professor at Arkansas State University, an Associated Faculty member with the University of Tennessee Health Sciences, and former CEO of a physical therapy company. As a translational neuroscientist, my research attempts to integrate the latest neurobiological research into rehab medicine to solve unmet clinical problems, including how to utilize lifestyle interventions and personalized medicine to treat mental illness and neurodegenerative disease. Therein I practice what I preach by paying attention to what I eat, how much I exercise, and making sure that I get enough sleep. ${ }^{*}$ cphillips@astate.edu

\section{AARON BALDRIDGE}

I graduated from Lyon College with majors in biology and psychology and a minor in French, and I am currently a third-year physical therapy student at Arkansas State University. My primary area of interest within physical therapy is geriatrics. I believe that we in physical therapy should be on the forefront of lifestyle modifications to improve health, particularly physical activity.
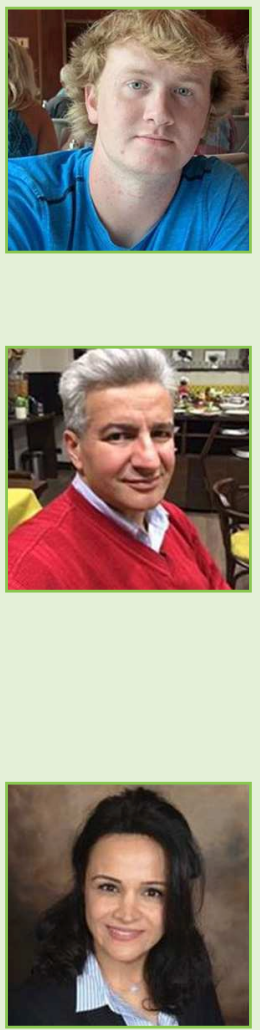

\section{COLIN PHILLIPS}

I am a second year college student working on a biology degree at Lyon College. I hope to go to medical school after I graduate. As a former football and baseball athlete, I know the importance of diet, fitness, and sleep in health and performance. I also know the importance of being mindful of lifestyle choices so that I can protect my brain and body as I age.

\section{MEHMET AKIF BAKTIR}

I am currently a lecturer in Erciyes University Faculty of Medicine, Department of Physiology. After graduating from Erciyes University Faculty of Medicine, I completed a specialization in medical physiology at the same university. Then, I worked as a doctor at a Bone Marrow Transplant Center for 2 years. Later, I worked for 2 years as a visiting researcher at Stanford University Medical School in the Department of Cardiovascular Medicine. Part of my current research interest is about how exercise can be used to protect the brain. I was born in 1973 in Turkey.

\section{ATOOSSA FAHIMI}

I am a physician-scientist working on Alzheimer's disease. I studied different aspects of neuroscience, such as memory, sleep, depression, stress, and addiction. Currently I am editing a clinical neurology handbook which will provide guidelines for clinicians. In my spare time, I exercise so as to improve my own memory and learning. I grew up in Iran, finished medical school in Europe, and completed a fellowship in neuroscience at Stanford Medical School. I believe we all can help humanity regardless to our ethnicity or background. 


\section{Our Mission}

To foster a love for science from a young age by involving young people in the peer-review process in the latest, cutting-edge research.

\section{How we do this?}

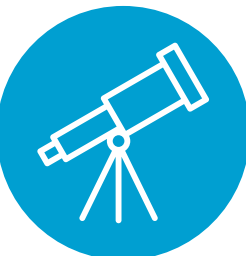

Astronomy and Space Science

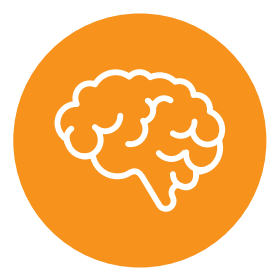

Neuroscience

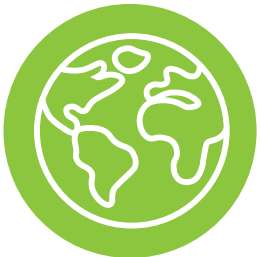

Earth

and its

Resources

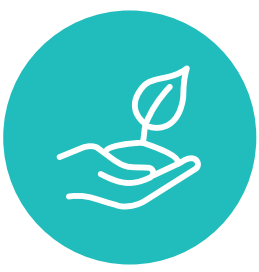

Biodiversity

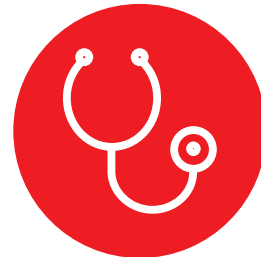

Health

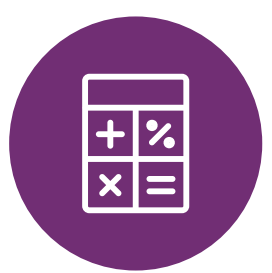

Mathematics

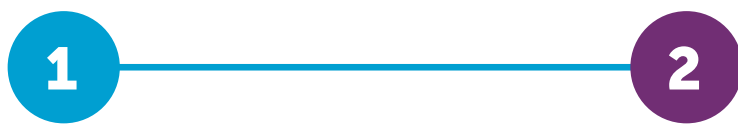

Our editorial board identifies recent discoveries. These can be articles published by any publisher.
The scientists behind the original research write an article that translates the discovery into terms accessible to the kids and teens. This new article is then submitted to Frontiers for Young Minds.

\section{3}

The Associate Editor assigns the manuscript to a Young Mind / Science Mentor pair, who produces a review report. The author must respond to this feedback point by point.

\section{4}

Once the review process is completed, the article is validated by the Associate Editor.

\section{5}

The finished article is published and made freely available on our website alongside the reviewers' names.

\section{6}

Educators from all around the world are free to create activities with their kids and teens based on the articles published.

We guarantee the protection of the Young Reviewers' identity and only publish their first names.

For more information:

www.kids.frontiersin.org • kids@ frontiersin.org • @ FrontYoungMinds 


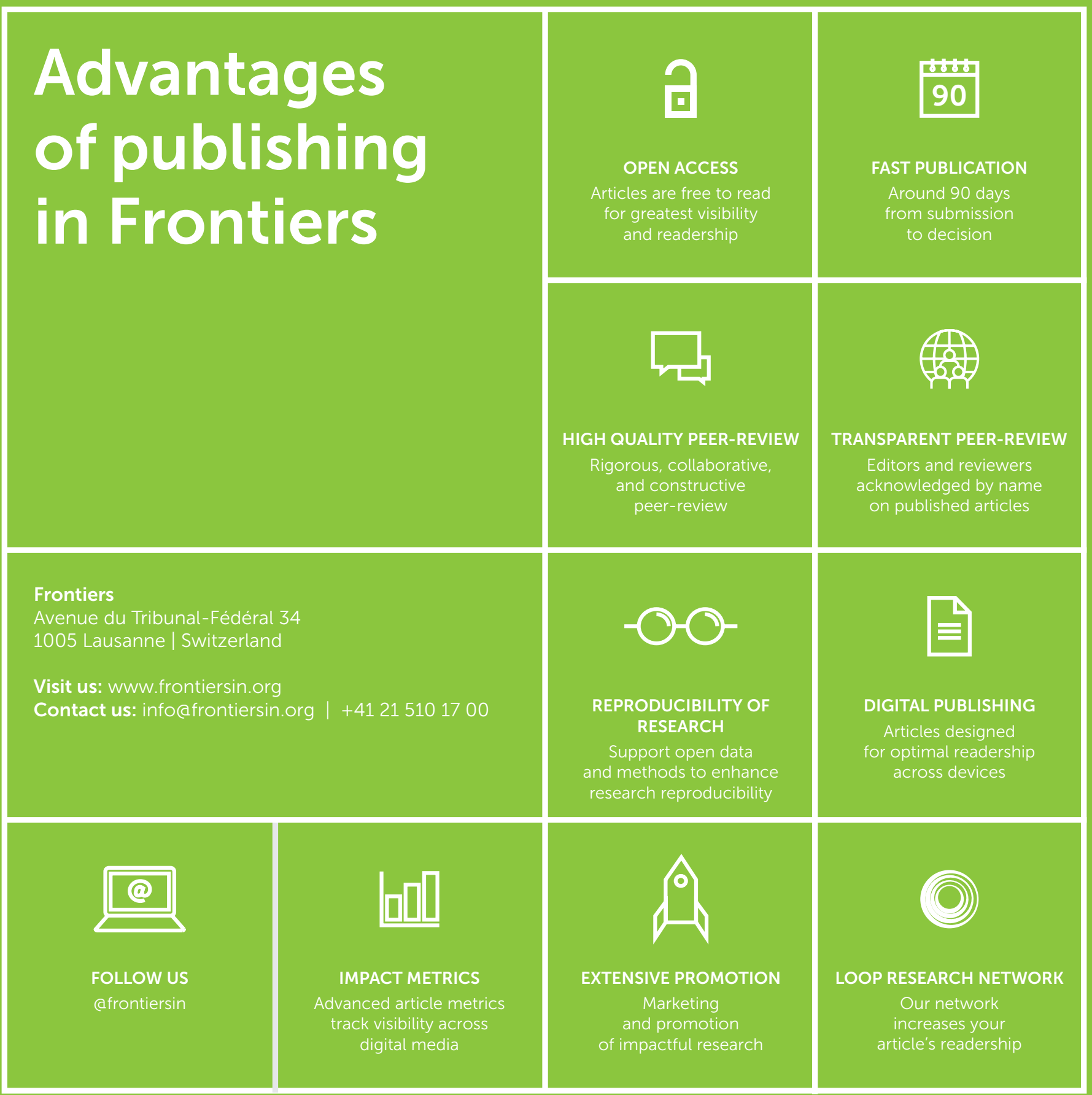

